\title{
Zachowane regesty z ksiąg metrykalnych parafii narolskiej z XVII-XVIII wieku
}

ZARYS TREŚCI:

SEOWA KLUCZOWE:
Rozwój badań nad zachowanymi księgami metrykalnymi (urodzeń, zawieranych małżeństw i zgonów) ma pierwszorzędne znaczenie nie tylko dla uszczegółowienia ustaleń genealogicznych poszczególnych rodów czy rodzin, ale przede wszystkim dla pogłębienia wiedzy o lokalnych społecznościach i zachodzących w ich obrębie procesów społecznych. Uprzystępnienie w różnych formach badaczom tej kategorii masowych źródeł historycznych może się w dłuższej perspektywie przyczynić do wyraźnego poszerzenia naszej wiedzy o różnorodnych zjawiskach demograficznych i stosunkach społecznych w obrębie żyjących przed wiekami pokoleń.

Narol, parafia Narol, szlachta województwa bełskiego, genealogia

ABSTRACT:

The development of studies on the extant church records (births, marriages and deaths) is of the utmost importance not only for specifying in detail the genealogical findings on particular lineages and families, but first and foremost for broadening the knowledge about local communities and social processes taking place within them. Different forms of making this category of mass historical sources accessible to scholars may contribute in the long run to distinctly widening our knowledge on diverse demographic 
phenomena and social relations within the generations living centuries ago.

KEYWORDS:

Narol, Narol parish, nobility of the Bełz voivodship (province), genealogy

Wzrastające w ostatnich dekadach zainteresowanie poszukiwaniami genealogicznymi zaowocowało m.in. pokaźnym przyrostem udostępnionych akt metrykalnych. Internetowe strony poszczególnych archiwów wypełnione są skanami zachowanych ksiąg metrykalnych poszczególnych parafii rejestrujących urodzenia (chrzty), zawierane małżeństwa i zgony. Pojawiło się szereg udostępniających tę kategorię źródeł portali i forów internetowych, nie brakuje też publikacji tradycyjnych ${ }^{1}$. Wartość badawczą metryk jako źródła historycznego trudno przecenić. Oprócz użyteczności dla ustaleń genealogicznych, stanowią one najczęściej podstawę badań nad szeroko rozumianym ruchem naturalnym ludności, $\mathrm{z}$ rodnością, umieralnością, migracjami, stosunkami rodzinnymi i gospodarstwem domowym włącznie ${ }^{2}$.

W Kościele rzymskokatolickim dokumentowanie w odrębnych księgach wykazu ochrzczonych i zaślubionych wprowadzono uchwałami soboru trydenckiego z 1563 r. Od roku 1614 obowiązek ten rozszerzono o rejestrację zmarłych. W potrydenckim Kościele polskim recepcja uchwał soborowych następowała z pewnym opóźnieniem, ale przed końcem XVI stulecia księgi ochrzczonych i zaślubionych zaprowadzone zostały we wszystkich diecezjach. Wykształcił się też w miarę jednolity formularz zapisów. Dla ksiąg ochrzczonych zawierał on datę chrztu (bez daty urodzenia), imię i stanowisko udzielającego sakramentu, imię chrzczonego dziecka, imię i nazwisko lub zawód oraz miejsce zamieszkania ojca, imię matki oraz imię i nazwisko lub zawód rodziców chrzestnych. Z czasem zaczęto też zamieszczać informację o tym, czy dziecko urodziło się w związku sakramentalnym. W zapisach dotyczących małżeństw określano dokładną datę ceremonii, imiona nupturientów uzupełnione o miejsce zamieszkania bądź informację o statusie społeczno-zawodowym, imiona i nazwiska

1 Tylko w ostatnich miesiącach ukazały się np. opracowane przez Roberta Jopa Metryki ślubów parafii pw. św. Marii Magdaleny w Łęcznej 1622-1768, Lublin 2020 czy przygotowana przez Dariusza Kupisza Księga metrykalna kościoła pod wezwaniem św. Michała Archanioła w Zebrzydowicach $z$ lat 1628-1776, Warszawa 2021.

2 Por. na ten temat uwagi w najnowszej publikacji: P. Rachwał, Ruch naturalny ludności rzymskokatolickiej w Lubelskiem w świetle rejestracji metrykalnej z lat 1582-190o, Lublin 2019, s. 77-149. 
świadków z podaniem ich miejsca zamieszkania, personalia celebransa i informację potwierdzającą ogłoszenie zapowiedzi. Choć w szczegółach formuła wpisów w poszczególnych parafiach mogła się nieco różnić, to nie były to różnice o istotnym znaczeniu, a i same procedury prowadzenia ksiąg metrykalnych nie uległy do schyłku XVIII w. radykalniejszym zmianom³ ${ }^{3}$.

Niestety, większość staropolskich ksiąg metrykalnych nie przetrwała późniejszych przypadków i zakrętów dziejowych. Taki los spotkał również akta metrykalne parafii w Narolu. Spłonęły one podczas pożaru miasteczka (w tym również kościoła) wywołanego przez wycofujące się 10 IX 1914 r. przed Rosjanami wojska austriackie. Rok później w piśmie do Konsystorza we Lwowie proboszcz narolski ks. Jan Niemczyk informował, iż „spłonęły też książki metrykalne i akta parafialne przechowywane w piwnicy [plebańskiej]” ${ }^{4}$. Były to z pewnością te same księgi, które miał w ręku kilka lat wcześniej Karol Notz, sporządzając inwentaryzację zabytków ówczesnego powiatu cieszanowskiego. Wśród innych starych ksiąg przechowywanych w narolskim kościele odnotował on wówczas również "Metryki od roku 1650 " 5 .

Nie były to jednak najstarsze narolskie zapisy metrykalne. Tamtejsza parafia ufundowana została przez Floriana Łaszcza Nieledewskiego, a jej uroczystej erekcji dokonał 16 lipca 1595 r. biskup chełmski Stanisław Gomoliński ${ }^{6}$. Ten sam Łaszcz kilka lat wcześniej rozpoczął w sąsiedztwie istniejącej od około 1568 r. wsi Narol lokację miasta Florianowa, na którą 2 października 1592 r. uzyskał przywilej królewski ${ }^{7}$. Rzecz przy tym charakterystyczna, że odchodząc od typowej wówczas praktyki umieszczania siedziby parafii w nowo budowanym mieście, Łaszcz zdecydował się na ulokowanie parafialnej świątyni pod wezwaniem Narodzenia Najświętszej Marii Panny na gruncie istniejącej już wsi (kościół filialny we Florianowie wybudował dopiero w 1617 r. Jerzy Łaszcz, syn i jeden ze spadkobierców Floriana). Najprawdopodobniej życie religijne wspólnoty wiejskiej w Narolu

3 Ibidem, s. 81-91.

4 Archidiecezja Lwowska obrządku łacińskiego w latach 1914-1918. Materiały źródłowe, t. 1, wyd. G. Chajko, Kraków 2018, s. 184.

5 S. P. Makara, J. Mazur, Materiały do dziejów Narola i Lipska, „Rocznik Lubaczowski”, t. 8,1998, s. 178 .

6 Szerzej o parafii zob. H. Gmiterek, Fundacja parafii w Narolu i jej losy w przedrozbiorowej Rzeczypospolitej, „Limes. Studia i Materiały z Dziejów Europy Środkowo-Wschodniej”, t. 11, 2018, s. 294-311.

7 Szerzej zob. R. Szczygieł, Lokacja Florianowa na tle urbanizacji Środkowego i Wschodniego Roztocza w XVI i pierwszej połowie XVII wieku, „Rocznik Lubaczowski”, t. 5, 1994, s. 5-16. 
rozkwitło znacznie wcześniej ${ }^{8}$, ustanowienie więc tam parafii było formą usankcjonowania istniejącego stanu faktycznego.

Wydaje się, że księgi metrykalne zaprowadzone zostały w narolskiej parafii już u samego jej zarania. W aktach wizytacji z 1604 r. wizytator zalecał jedynie większą staranność w ich prowadzeniu i wyodrębnienie metryki ochrzczonych od zaślubionych ${ }^{9}$. W 1629 r. odnotowano w kościele narolskim cztery metryki: ochrzczonych, zawartych małżeństw, wykaz parafian podczas kolędy oraz księgę z zapisami legatów i jałmużn ${ }^{10}$. Również w 1639 r. przeprowadzający wizytację wikariusz generalny Jan Sasin odnotował istnienie jednej, wspólnej księgi z zapisami chrztów i ślubów, wytykając jedynie brak w notach odnoszących się do ma1żeństw informacji o trzech poprzedzających ślub zapowiedziach oraz postulując, by księga metrykalna prowadzona była przez proboszcza, a nie przez kościelnego (dzwonnika) ${ }^{11}$. Ważne te dla dziejów społeczności narolskiej źródła padły wszakże najprawdopodobniej pastwą pożaru, jaki dotknął Florianów i kościół narolski w początkach listopada 1648 r., gdy te strony zostały spustoszone przez idące pod Zamość kozacko-tatarskie zagony Bohdana Chmielnickiego ${ }^{12}$.

Nowe księgi metrykalne zaprowadzone zostały najpewniej dopiero w 1650 r., co potwierdza również przywołana wyżej nota K. Notza. Informacja Ludwika Zielińskiego, autora interesujących nas tu wypisów, który pisząc w 1841 r. o swojej wizycie w Narolu, podczas której miał w „metrykach kościelnych” znaleźć zapiskę: „Zamykam księgi metryk, bo nieprzyjaciel z ogniem i mieczem zbliża się do Narola"13, sugeruje co prawda, że miał on w ręku księgę sprzed dewastacji Narola przez Kozaków, ale wydaje się ona jedną z licznych tego autora licentiarum poeticarum. Gdyby rzeczywiście księga taka przetrwała i Zieliński miałby do niej dostęp, z pewnością znalazłoby to odzwierciedlenie w sporządzonym przez niego repertorium. Tymczasem jego najstarsze wypisy również odnoszą się do roku 1650. Zdaje się to przesądzać, że najstarsze metrykalia narolskie uległy zatracie już w $1648 \mathrm{r}$.

8 Pierwsza wzmianka o proboszczu narolskim (presbyter parochus Narolensis) pochodzi z 1588 r. Być może był to jeden z częściej wówczas spotykanych księży wędrownych, zaspokajających potrzeby duszpasterskie żyjących w diasporze grup ludności, H. Gmiterek, op. cit., s. 296.

9 Archiwum Archidiecezjalne w Lublinie, Akta Konsystorza Chełmskiego (dalej: AAL, AKCh), Rep. 60 A, 149, k. 85v.

10 Ibidem, k. 130

11 AAL, AKCh, Rep. 60 A, k. 129.

12 Por. E. Janas, Narol na mapie polskich dziejów wojskowych XVII wieku, „Rocznik Lubaczowski", t. 5, 1994, s. 39-41.

13 L. Zieliński, Narol - Lubycza - Rawa - Źółkiew, „Lwowianin” 1842, z. 2, s. 50. 
W świetle powyższych uwag należy skonstatować, że publikowane niżej zapiski z narolskich ksiąg metrykalnych stanowią jedyną z okresu staropolskiego pozostałość źródłową, rejestrującą - w niewielkim tylko fragmencie - materię należącą do szeroko rozumianego ruchu naturalnego ludności na terenie nazywanym dziś umownie Narolszczyzną. Pokrywał się on z granicami narolskiej parafii, do której należało miasto Florianów oraz wsie Narol, Kadłubiska, Chyże i Podlesina. Wykaz zawiera w sumie 546 notat $\mathrm{z}$ lat 1650-1796, w zdecydowanej większości odnoszących się do urodzeń, tylko 29 zapisów dotyczy zawieranych małżeństw. Trudno te liczby odnieść do rzeczywistej statystyki aktów chrztu i ślubów zapisanych w metrykach, z pewnością stanowią one jedynie ułamek zawartości utraconych dziś bezpowrotnie ksiąg metrykalnych. Wystarczy dodać, że w świetle najstarszej z zachowanych dziś metryk kościoła narolskiego w samym tylko roku $1818 \mathrm{w}$ parafii odnotowano 76 urodzeń ( 35 w Narolu Mieście, 26 w Narolu wsi, 8 w Kadłubiskach, 4 w Chyżach i 3 w Podlesinie), 26 małżeństw oraz 21 zgonów $^{14}$.

Interesujący nas rękopis nosi dziś tytuł „Metryki chrztu świętego i ślubu w kościele narolskim obwodu żółkiewskiego z różnych lat. $\mathrm{Z}$ archiwum Ludwika Wittelius Ciołek Zielińskiego dziedzica Lubyczy Królewskiej. Wartość 100 fl.” i stanowi część przechowywanej w Archiwum Głównym Akt Dawnych w Warszawie kolekcji zgromadzonej przez Aleksandra Czołowskiego, zasłużonego (do czerwca 1939 r.) dyrektora Muzeum i Archiwum Miasta Lwowa (zespół nr 388: Zbiór Aleksandra Czołowskiego) ${ }^{15}$. W obrębie zbioru oznaczony jest sygnaturą 504; pod sygnaturą 508 mieści się niepełna - zaczynająca się dopiero od litery D - kopia pisana inną ręką. Sądząc po dukcie pisma, wypisy sporządził osobiście Ludwik Zieliński, znany, choć nie cieszący się najlepszą sławą heraldyk, genealog, literat, księgarz, kolekcjoner, redaktor i wydawca "Lwowianina” $(1835-1842)^{16}$. W 1843 r. osiadł on w nabytych drogą licytacji dobrach Lubycza Królewska, gromadząc w tamtejszym dworze pokaźną bibliotekę i archiwum. Zebrał tam spory zbiór wypisów $\mathrm{z}$ różnych akt przechowywanych $\mathrm{w}$ archiwach, głównie lwowskich, a także ekstraktów z ksiąg metrykalnych okolicznych para-

14 Archiwum Państwowe w Przemyślu, Kopie akt metrykalnych parafii dekanatu lubaczowskiego archidiecezji lwowskiej obrządku rzymskokatolickiego, sygn. 186, k. 2-14.

15 Więcej zob. T. Zielińska, Zbiór Aleksandra Czołowskiego w Archiwum Głównym Akt Dawnych, „Archeion”, t. 89, 1991, s. 37-60.

16 O jego działalności zob. więcej Literatura w Galicji (1772-1848). Ustęp z pamiętnika Władysława Zawadzkiego, Lwów 1878, s. 107-109; Ł. Charewiczowa, Historiografia i miłośnictwo Lwowa, Lwów 1938, s. 54-57. 
fii. Wykorzystywał je głównie do celów komercyjnych, zwłaszcza gdy władze zaborcze nakazywały szlachcie na nowo legitymować się ze szlachectwa. Służył wówczas swoimi zasobami poszukującym korzeni ziemianom, nie stroniąc ponoć od fabrykowania dyplomów i nadawania różnych tytułów. Miał się na tym dorobić niezłej fortuny, co umożliwiło mu nabycie dóbr lubyckich. W Lubyczy zamieszkiwał do roku 1868, gdy pozbył się majątku i powrócił do Lwowa. Tam zmarł w 1873 r. ${ }^{17}$ Jego synem był Władysław Kornel Zieliński, autor m.in. wydanej w 1878 r. „Monografii Lublina”, będącej pierwszą próbą całościowego ujęcia historii grodu nad Bystrzycą ${ }^{18}$.

Po śmierci Ludwika Zielińskiego jego zbiory długo pozostawały w posiadaniu rodziny, by w 1892 r. znaleźć swoje miejsce w Archiwum miasta Lwowa. Wiosną 1944 r., podczas wojennej zawieruchy, udało się Aleksandrowi Czołowskiemu, wówczas już emerytowanemu dyrektorowi Archiwum, przesłać do Krakowa 36 skrzyń zawierających znaczną część zgromadzonej kolekcji. Przesyłka została ukryta w Tyńcu, gdzie rękopisy pozostawały do końca wojny. Dziedziczką kolekcji stała się córka Czołowskiego Stanisława Karczewska, która w 1947 r. sprzedała ją Bibliotece Narodowej. Rękopisy zostały wówczas poddane selekcji, podczas której wyłączono z kolekcji te uznane za archiwalne i przekazano je Archiwum Głównemu Akt Dawnych. Stanowią dziś one w zasobie Archiwum zespół nr 388.

W pozostałej po L. Zielińskim kolekcji odnaleźć można wypisy z metryk sporządzone przez niego samego bądź przez osoby, którym takie zadanie zlecał, często za odpłatnością. Pod sygnaturą 507 mieszczą się np. notaty z parafii w Warężu, które „wypisał z ksiąg kościelnych ksiądz Marceli Łapczyński, ... a w alfabet ułożył Ludwik de Zieliński, dziedzic Lubyczy Królewskiej obwodu żółkiewskiego, c.k. w Morawii, Szląsku, Krakowie oraz imperatorskiego w St. Petersburgu towarzystw uczonych członek honorowy dla archiwum lubyckiego, 1860". Wyciągi z metryk narolskich wyszły spod pióra samego Zielińskiego, który w latach 1847-1852 nawiązał bliskie relacje z rezydującym w Narolu komisarzem skarbowym Konradem Lamem, ojcem znanego później powieściopisarza Jana Lama. Z pewnością zaprzyjaźnił się wówczas również z proboszczem narolskim Aleksandrem Grądzkim (1845-1853), a także z jego następcą Michałem Miernickim (1853-1869). Korzystając z ich gościny, odnajdywał w metrykach

17 O lubyckim okresie L. Zielińskiego zob. ostatnio: Z. Pizun, R. Gawryś, Właściciele ziemscy w miasteczku Lubycza Królewska (1787-1939), „Rocznik Tomaszowski”, R. 6, 2017, s. 29-33.

18 Reprint (z posłowiem H. Gmiterka): Lublin 2009. 
przede wszystkim interesujące go rodziny szlacheckie bądź nazwiska wskazujące na szlachecki rodowód ich nosicieli, choć nie pomijał również mieszczan, zwłaszcza gdy przy ich nazwisku odnajdywał informacje o pełnionych przez nich funkcjach (burmistrz, wójt, rajca, nauczyciel). W dwu przypadkach odnotował występujące w metryce określenia famatus (237) bądź spectabilis (147), oznaczające przynależność do stanu mieszczańskiego. Ostatecznym rezultatem tych prac było sporządzenie „indeksu” - jak sam najczęściej określał rezultaty swych trudów - zawierającego 546 zapisek uporządkowanych alfabetycznie według nazwisk, w obrębie zaś każdej litery - z niewielkimi odstępstwami - chronologicznie. Ten właśnie wykaz jest przedmiotem poniższej edycji.

Forma sporządzonych przez Zielińskiego notat z pewnością zubaża nieco treść oryginalnych zapisów metrykalnych. Nie mając do dyspozycji metryk narolskich, posłużmy się dla przykładu zapisami z ksiąg metrykalnych sąsiedniej parafii w Tomaszowie, które z pewnością nie odbiegają od tych, jakie znaleźlibyśmy w księgach narolskich. Zapis odnoszący się do dzieci mieszczan bądź z rodzin chłopskich nie był nadmiernie rozbudowany, zawierał przede wszystkim datę chrztu (bez daty urodzenia), po której - w przywoływanym tu przypadku 21 maja 1669 r. - następowała formuła: Reverendus pater Casimirus Kierzkowski vicarius [ecclesiae Thomaszoviensis] baptisavit Nicolaum, Martini Rudnicki et Fedorae coniugum legitimorum. Patrini fuerunt Laurentius Wisniowski et Magdalena Licholacka de Thomaszów. Nieco bardziej rozwiniętą formułę przyjmowano dla noworodków z rodzin szlacheckich. Na tej samej stronie tomaszowskiej księgi urodzeń znajduje się zapis o chrzcie 8 maja 1669 r. syna Mikołaja Stefana Radeckiego: Ego Laurentius Irzykowski commendarius ecclesiae Thomaszoviensis, baptisavi Christophorum, generosi domini Nicolai Stephani Radecki centuriorum cohortis magnifici domini Joannis Myszkowski sucamerarii Bełzenzis palatinatus et Theresiae Joannem coniugum legitimorum. Patrini fuerunt illustrissimus dominus Joannes in Złoczów et Źółkiew Sobieski supremus Regni marschalcus et generalis exercituum dux, Javoroviensis, Striiensis, Calussiensis etc. praefectus cum generosa domina Catharina Sokołówna ${ }^{19}$. Dowiadujemy się z niego nieco więcej zarówno o rodzicach dziecka, jak i o chrzestnych. W każdym przypadku odstęp czasu między urodzeniem się dziecka a jego chrztem nie powinien był przekraczać 8-9 dni, a w XVIII w. termin ten skrócono do $3 \mathrm{dni}^{20}$.

19 Archiwum Państwowe w Lublinie (dalej: APL), Akta parafii rzymskokatolickiej w Tomaszowie, sygn. 1, s. 27.

20 P. Rachwał, op. cit., s. 79-80. 
W wypisach Zielińskiego daty chrztu zostały potraktowane jako daty urodzin, pominięte zostały natomiast informacje o rodzicach chrzestnych (wzmianki o nich są nieliczne; $115,276,284,286,461$ ). Poza sporadycznymi przypadkami opuszczone też zostały informacje o miejscach pochodzenia rodziców i chrzestnych oraz o ich zajęciach, które zapewne w oryginałach metryk występowały. Autor notat nie pominął natomiast niektórych ciekawostek, jak tej o pochodzeniu żony Jana Jankowskiego de gente Cyganorum (182) czy o urodzeniu się w 1792 r. małżonkom Annie i Janowi Skibińskim bliźniaków (502). Warto także zauważyć kilkanaście odnoszących się do lat 50. XVII w. zapisów o pochodzeniu matek chrzczonych noworodków z odbudowującego się po kozackiej pożodze Florianowa.

Również noty Zielińskiego o zawartych w narolskim kościele małżeństwach nie oddają pełnej treści zapisów metrykalnych. Odwołując się do księgi zaślubionych parafii tomaszowskiej, przywołajmy przykładowo zapis z 17 maja 1665 r.: Ego Andreas Filewicz commendarius ecclesiae Thomaszoviensis matrimonium contractum inter Martinum Wilczoczek et Sophiam Woznionka de Narole, tribus denuntiationibus praemissis confirmavi. Ad stantibus testibus Andrea Panyskora et Francisco Mazurek de Thomaszow ${ }^{21}$. Z tak rozbudowanej formuly w wersji Zielińskiego pozostały właściwie - poza datą - jedynie imiona i nazwiska nupturientów, czasami z dodatkową informacją o nowożeńcu, jak np. o Franciszku Okorskim, administratorze wsi Chotylub w 1747 r. (406). Pominięte zostały natomiast zupełnie nazwiska świadków.

W publikowanych wypisach Ludwika Zielińskiego z nieistniejących już dziś ksiąg metrykalnych parafii narolskiej z XVII-XVIII w. zachowane zostały specyficzne formy ich autora, jak np. zapisy decembris, decembra odnoszące się do nazwy miesiąca. Ingerencja wydawcy ograniczyła się do nadania poszczególnym wpisom numerów porządkowych, ujednolicenia skrótów: ur. - urodzony, nob. - nobilis (szlachetny), gen. - generosus (urodzony jako określenie statusu szlacheckiego). Tekst źródła uzupełniony został o indeks wszystkich występujących w nim osób oraz o chronologiczne zestawienie wpisów. Wypisy z metrykalnej księgi zaślubin mieszczą się pod numerami: 23, 44-46, 77, 90, 91, 118, 139, 163, $175,234-236,329,330,378,395,396,406,420,437-439,471,485-487,528$.

${ }^{21}$ APL, Akta parafii rzymskokatolickiej w Tomaszowie, sygn. 9, s. 7. 


\section{Tekst źródła}

Or.: Archiwum Główne Akt Dawnych w Warszawie, Zbiór Aleksandra Czołowskiego, sygn. 504 , s. $1-70$.

[s. 1] Metryki chrztu świętego i ślubu w kościele narolskim obwodu żółkiewskiego z różnych lat. Z archiwum Ludwika Wittelius Ciołek Zielińskiego dziedzica Lubyczy Królewskiej. Wartość $100 \mathrm{fl}$.

[1] [s. 2] Axan Marianna Agneta, córka nob. ac gen. Petri et Agnetis de Krzynickie Axanów notariorum curiae, ur. 30 decembra r. 1770

[2] Axan Salomeia Katarzyna, córka gen. Petri et Agnetis de Krzynickie Axanów, ur. 17 november r. 1774

[3] [s. 3] Bielecki Jan, syn Laurentego i Elżbiety z Rudy Rybnickiej, ur. 17 iunii r. 1653

[4] Białobocki Sebastian, syn Alexandra i Zofii z Florianowa, ur. 20 ianuarii r. 1655

[5] Bielecki Piotr, syn Laurentego i Elżbiety z Rudy Rybnickiej, ur. 25 iunii r. 1656

[6] Bojarski Paweł, syn Stanisława i Zofii, ur. 4 februarii r. 1658

[7] Burzyński Mathias, syn Tomasza Burzyńskiego de Krasnobród i Marianny, ur. 15 februarii r. 1674

[8] Baranowski Mathias, syn Jana Baranowskiego i Reginy, ur. 12 februarii r. 1675

[9] Baranowski Gregorius, syn Mathiae i Reginy, ur. 10 marca r. 1680

[10] Bielski Mathias, syn Andrzeja i Zofii, ur. 18 februarii r. 1681

[11] Brzozowski Szymon Maurycy, syn Alexandra i Jadwigi, ur. 27 octobris r. 1683

[12] Brzozowski Walenty, syn Alexandra i Jadwigi, ur. 13 februarii r. 1687

[13] [s. 4] Bukowski Antoni Dominik, syn gen. Michała Bukowskiego i Gryzeldy de Kossobudy, ur. 15 kwietnia r. 1687

[14] Bogusz Franciszek, syn Jakuba i Mariny, ur. 31 augusta r. 1687

[15] Bogusz Mikołaj, syn Jakuba i Mariny, ur. 13 decembra r. 1690

[16] Bielecki Franciszek, syn Szymona, ur. 30 septembra r. 1691

[17] Borkowski Stanisław, syn nob. Joanni Borkowski i Teresy, ur. 31 augusta r. 1692

[18] Bielecki Tomasz, syn Mikołaja i Reginy, ur. 2 novembra r. 1694

[19] Bojanowicz Andrzej, syn Jana i Maryi, ur. 20 novembris r. 1701

[20] Bielecki Marcin, syn Mikołaja i Reginy, ur. 29 octobra r. 1702

[21] Brzozowski Sebastian, syn Mathiae i Jadwigi, ur. 15 ianuarii r. 1706

[22] Bojanowicz Mathias, syn Jana i Maryjanny, ur. 8 februarii r. 1706

[23] [s. 5] Bystrzejowski Michał nobiles z Maryjanną Czajkowską wziął ślub 6 februarii r. 1725

[24] Bielecki Albert, syn Mikołaja i Katarzyny, ur. 29 maja r. 1709

[25] Bojanowicz Szymon, syn Jana i Maryjanny, ur. 11 octobra r. 1709 
[26] Bielecki Jakub, syn Andrzeja i Katarzyny, ur. 25 iulii r. 1710

[27] Brzozowski Laurenty, syn Jana i Katarzyny, ur. 27 iulii r. 1710

[28] Bielecki Michał, syn Adama i Klary, ur. 9 septembris r. 1710

[29] Bielecki Tomasz, syn Andrzeja i Katarzyny, ur. 10 decembris r. 1713

[30] Bielecki Adam, syn Adama i Klary Drozdówny, ur. 9 iunii r. 1720

[31] Bielecki Jan, syn Adama i Klary, ur. 17 iunii r. 1723

[32] [s. 6] Bielecki Adalbertus, syn nob. Pauli Bieleckiego i Maryjanny, ur. 23 aprilis r. 1724

[33] Blamowski Mathias, syn Szymona i Maryjanny, ur. 12 februarii r. 1726

[34] Bielecki Andrzej, syn Adama i Ewy, ur. 20 novembris r. 1730

[35] Bielecki Szymon, syn Adama i Ewy, ur. 25 octobra r. 1744

[36] Bielecki Bernard, syn Tomasza i Hedwigi, ur. 20 maii r. 1748

[37] Bielecki Walenty, syn Adama i Ewy, ur. 14 februarii r. 1751

[38] Blamowicz Mikołaj, syn Szymona i Anastazji, ur. 4 novembra r. 1754

[39] Borkowski Mathias, syn Antoniego i Katarzyny, ur. 19 februarii r. 1758

[40] Babecki Antoni Marcin Kajetan, filius gen. Cajetani Babecki gubernatorii Naroliensis et Euphrosinae, ur. 1 decembra r. 1761

[41] [s. 7] Botuliński Józef, syn Laurentego i Maryjanny, ur. 18 februarii r. 1762

[42] Botuliński Laurenty, syn Michała i Maryjanny, ur. 7 iulii r. 1763

[43] Bielecki Krzysztof, syn Bartłomieja i Maryjanny, ur. 2 augusta r. 1763

[44] Bunt Joannes nob. capitanum de Zamość z Teresą Krauzewską ślub 19 iulii r. 1736

[45] Bielecki Tomasz z Jadwigą Suską ślub 29 ianuarii r. 1747

[46] Bzowski Josephus generosus de Wólka Podhorce z Elżbietą Mogilnicką de villae Chyże ślub 25 februarii r. 1759

[47] Botuliński Laurenty, syn Franciszka i Maryjanny, ur. 1 iulii r. 1768

[48] Boreyko Jan Kapistron Szymon, syn Mathiae i Jadwigi Pudełkówny, ur. 25 octobris r. 1785

[49] Bielecki Christophorus Michael, syn Błażeja i Maryjanny, ur. 21 septembris r. 1770

[50] Bielecki Mathias Josephus, syn Bartłomieja i Maryjanny, ur. 23 februarii r. 1771

[51] [s. 8] Bielecki Andrzej, syn Błażeja i Maryjanny, ur. 30 novembris r. 1773

[52] Bielecki Jakub, syn Błażeja i Maryjanny, ur. 3 iulii r. 1776

[53] Botuliński Piotr, syn Jakuba i Agnety, ur. 19 octobra r. 1780

[54] Bielecki Jan, syn Barnaby Błażeja i Maryjanny, ur. 17 iunii r. 1783

[55] Bielecki Hieronim, syn Błażeja i Marianny Mulakówny, ur. 12 augusta r. 1786

[56] [s. 9] Chmielecki Mathias, syn Jakuba i Anny z Florianowa, ur. 16 februarii r. 1652

[57] Chojecki Stanisław, syn Stanisława i Teofili de Ruda Rybnicka, ur. 11 maii r. 1652

[58] Chmielecki Gregorius, syn Jakuba i Anny z Florianowa, ur. 9 maii r. 1654

[59] Chojecki Casimirus, syn Stanisława i Teofili de Ruda Rybnicka, ur. 20 iulii r. 1654 
$[61]^{1}$ Chmielecki Albert, syn Jakuba i Anny, ur. r. 165419 aprila

[62] Chojecki Franciszek, syn Stanisława i Teofili, ur. 17 stycznia r. 1661

[63] Chmielecki Szymon, syn Jakuba i Katarzyny, ur. 26 octobris r. 1670

[64] Czerwiński Kazimierz, syn Jana i Reginy, ur. 4 marca r. 1679

[65] Czerwiński Michał, syn Jana i Reginy, ur. 25 septembris r. 1681

[66] Czerwiński Christophorus, syn Jana i Reginy, ur. 17 septembra r. 1683

[67] Czerwiński Albert, syn Pawła i Zuzanny, ur. 4 februarii r. 1687

[68] [s. 1o] Czarnołuski Andrzej, syn Sebastiana i Mariny, ur. 24 novembris r. 1689

[69] Czerniecki Laurenty, syn Marcina i Anny, ur. 4 augusta r. 1694

[70] Czarniowski Albert, syn Alberta i Zofii, ur. 15 aprilis r. 1696

[71] Czarnołuski Laurenty, syn Sebastiana i Anny, ur. 5 augusta r. 1696

[72] Czernecki Jakub, syn Marcina i Zofii, ur. 20 iulii r. 1697

[73] Czechowski Jacobus, syn nob. Stanislai Czechowski i Anny, ur. 27 iulii r. 1700

[74] Cichowski Kazimierz, syn Sebastiana i Katarzyny, ur. 1 marca r. 1700

[75] Czuryło Jan, syn Jana i Katarzyny, ur. 1 ianuarii r. 1703

[76] Chmielecka Anna, córka gen. Martiani Chmielecki i Urszuli Łaszczównej de Neledow, ur. 21 iulii r. 1703

[77] [s. 11] Częntkowski Franciscus generosus de villae Choryniec z Katarzyną Stocką wziął ślub 8 aprilis r. 1722

[78] Cykowski Andrzej, syn nob. Theodori Cykowskiego i Reginy, ur. 8 novembris r. 1714

[79] Czerniawski Józef, syn Alberta i Ewy, ur. 22 marca r. 1723

[8o] Częntkowska Agneta, córka gen. Joannis ${ }^{2}$ i Katarzyny, ur. 29 ianuarii r. 1725

[81] Cichowski Błażej, syn Alberta i Reginy, ur. 25 februarii r. 1725

[82] Cichowski Tomasz, syn Alberta i Reginy, ur. 11 decembra r. 1727

[83] Cichowski Maciej, syn Alberta i Reginy, ur. 9 februarii r. 1734

[84] Chociwski Ignacy Michał, syn nob. Adalberta i Anny Chociwskich, ur. 23 augusta r. 1750

[85] Chudzicki Antoni, syn Jana i Katarzyny, ur. 7 iunii r. 1752

[86] Chudzicki Adalbert Adam, syn Jana i Katarzyny, ur. 18 kwietnia r. 1755

[87] [s. 12] Czyżewski Sebastianus, filius gen. Joanni et Joanna Czyżewskich, ur. 18 stycznia r. 1758

[88] Chudzicki Jakub, syn Jana i Katarzyny, ur. 23 iulii r. 1758

[89] Chudzicki Benedykt Józef, syn Jana i Katarzyny, ur. 23 marca r. 1760

1 Pomyłka wydawcy. Cykl wydawniczy spowodowat, że nie udało się dokonać poprawki w numeracji wpisów. W indeksie osobowym pod numerami jak w edycji źródła.

2 Zapewne tożsamy z Franciszkiem Częntkowskim, zob. nr 77. 
[90] Cykowski Georgius nobiles z Maryjanną Lisowską ślub 8 augusta r. 1734

[91] Czyżowski Joannes generosus de villae Podhorce z Joanną Mogilnicką de villae Chyże ślub 31 octobris r. 1756

[92] Chudzicki Mateusz Michał, syn Jana i Katarzyny, ur. 21 septembris r. 1762

[93] Ciążyński Jan Antoni Michał, filius magnifici ac gen. Antonii et Mariae Egiptianae de Bystrzykowskie Ciążyńskich, ur. 8 augusta r. 1773

[94] Chorbaszewski Antoni Jan, syn nob. Adalberti et Anna Chorbaszewskich, ur. 6 maii r. 1777

[95] [s. 13] Ciążyński Felix Antonius Joannes, syn Antoniego et Mariae Egiptianae Ciążyńskich, ur. 10 maii r. 1778

[96] Ciążyński Andrzej, syn nob. Antonii et Mariae Egiptianae Ciążyńskich, ur. 30 decembra r. 1779

[97] Chudzicki Jan Antoni, syn Jakuba i Maryjanny, ur. 28 maii r. 1781

[98] Chomicki Michał, syn Michała i Marianny, ur. 22 augusta r. 1784

[99] Chudzicki Paweł, syn Jakuba i Marianny, ur. 21 ianuarii r. 1785

[10o] Chomicki Franciszek, syn Michała i Zofii, ur. 24 septembra r. 1786

[101] Czarniecka Honorata, córka nob. Jana Czarnieckiego i Anny de Lipskie, ur. 21 ianuarii r. 1787

[102] [s. 14] Dobrucki Albert, syn Marcina i Barbary z Rudy Rybnickiej, ur. 17 aprila r. 1656

[103] Dobrucki Stanislaus, syn Marcina i Barbary, ur. 15 septembra r. 1658

[104] Dobrucki Albertus, syn Christopheri i Anny, ur. r. 165927 aprila

[105] Duchnicki Marcin, syn Jana sutoris [i Jadwigi], ur. 22 octobra r. 1673

[106] Duchnicki Kazimierz, syn Jana i Jadwigi, ur. 28 marca r. 1675

[107] Dąbrowski Marcin, syn Mikołaja i Anny, ur. 13 novembra r. 1677

[108] Dzikowski Walenty, syn Jana i Anny, ur. 6 februarii r. 1679

[109] Dobrucki Sebastian, syn Alberta i Agnety, ur. 11 ianuarii r. 1685

[110] Dydyński Antoni, syn gen. Antoniego Christophora i Barbary Dydyńskich, trzymał do chrztu świętego Mikołaj Głębocki, ur. 1 maii r. 1686

[111] Dobrucki Bartłomiej, syn Alberta i Agnety, ur. 11 augusta r. 1687

[112] Dobrucki Marcin, syn Alberta i Agnety, ur. 13 novembra r. 1689

[113] Duchnicki Jan, syn Andrzeja i Zofii, ur. 8 septembra r. 1692

[114] Dąbrowski Marcin, syn Jana i Katarzyny, ur. 12 novembra r. 1702

[115] [s. 15] Dziewałtowski Gintoft Antoni Kazimierz, syn gen. domini Joanni Gintoft Dziewałtowski capitanaei Terleszynensis et Victoriae Silnicka coniugum legitimorum. Patrini fuerat gen. Joannes Silnicki et Anna Kulikowska, gen. Andreas Kulikowski et Magdalena Silnicka, ur. 17 decembris r. 1710

[116] Dworzański Sebastian, syn Mikołaja i Maryjanny, ur. 1 ianuarii r. 1704 
[117] Dąbrowski Kazimierz, syn Jana i Maryjanny ${ }^{3}$, ur. 25 februarii r. 1705

[118] Dubrawski Adalbert z Sanoka z Maryjanną Mazurkówną wziął ślub 25 maii r. 1722

[119] Dobrzycki Andrzej, syn Kazimierza Dobrzyckiego wojskowego i Heleny, ur. 26 novembris r. 1708

[120] Dobrucki Jakub, syn Mikołaja i Katarzyny, ur. 10 iulii r. 1714

[121] Duchnicki Andrzej, syn Łukasza i Hedwigi, ur. 25 novembra r. 1719

[122] [s. 16] Dobrucki Bartłomiej, syn Bartłomieja i Reginy Dwornikówny, ur. 26 augusta r. 1720

[123] Duchnicki Piotr, syn Łukasza i Hedwigi, ur. 28 iunii r. 1722

[124] Dobrucki Mathias, syn. nob. Martini Dobrucki i Agnety, ur. 17 ianuarii r. 1724

[125] Dobrucki Albert, syn Bartłomieja i Reginy, ur. 27 marca r. 1727

[126] Dobrucki Jan, syn Bartłomieja i Reginy, ur. 30 novembra r. 1730

[127] Dobrucki Józef, syn Marcina i Agnety, ur. 14 februarii r. 1733

[128] Dworzański Michał, syn Antoniego i Zofii, ur. 26 iulii r. 1733

[129] Dobrucki Łukasz, syn Marcina i Agnety, ur. 9 octobris r. 1740

[130] Dobrucki Michał, syn Bartłomieja i Katarzyny, ur. 17 septembra r. 1750

[131] Dobrucki Michał, syn Bartłomieja i Katarzyny, ur. 29 septembra r. 1751

[132] Dobrucki Tomasz, syn Bartłomieja i Katarzyny, ur. 21 decembra r. 1754

[133] [s. 17] Domaszewski Dominik, syn Sebastiana i Katarzyny, ur. 3 augusta r. 1755

[134] Dobrucki Sebastian, syn Michała i Jadwigi, ur. 20 stycznia r. 1756

[135] Dobrucki Mathias, syn Michała i Jadwigi, ur. 20 februarii r. 1760

[136] Dobrucki Jan Kanty, syn Bartłomieja i Katarzyny, ur. 19 octobra r. 1760

[137] Dombrowski Ignacy, syn Józefa i Anastazji, ur. 28 iulii r. 1762

[138] Dobrucki Adalbert, syn Bartłomieja i Katarzyny, ur. 5 aprila r. 1763

[139] Drygalski Joannes generosus, z Antoniną Syroczyńską ślub 10 februarii r. 1743

[140] Domaszewski Maciej, syn Sebastiana i Katarzyny, ur. 8 februarii r. 1762

[141] Dąbrowski Albin Kazimierz, syn gen. Thadaei et Catharinae Dąbrowskich, ur. 4 marca r. 1764

[142] Dobrucki Adalbert, syn Michała i Jadwigi, ur. 23 marca r. 1766

[143] [s. 18] Dobrucki Krzysztof, syn Michała i Jadwigi, ur. 4 septembris r. 1768

[144] Dąbkowski Dominik, syn Laurentego i Maryjanny, ur. 29 iulii r. 1787

[145] Dobrucki Adalbert, syn Szymona Dobruckiego i Teresy subdapiferi żytomiriensis, ur. 23 aprilis r. 1791

[146] Dobrucki Marcin, syn Tomasza i Maryjanny, ur. 11 novembris r. 1792

3 Możliwy błąd kopisty, zamiast: Katarzyny, por. $n r 114$. 
[147] Domaszewski Jan Melchior Gaspar, syn spectabili domini Domaszewski i Elżbiety de Chodziejowskie, ur. 24 ianuarii r. 1796

[148] Dobrucki Antoni Felix, syn Tomasza i Maryjanny Wolańczykówny, ur. 26 maii r. 1796 [149] Dobrucki Piotr Paweł, syn Mathiae Dobruckiego i Maryjanny Szumilak, ur. 1 novembris r. 1796

[150] [s. 19] Frankowski Józef, syn Stanisława i Elżbiety z Wólki Łosinieckiej, ur. 21 marca r. 1655

[151] [s. 20] Guszkowski Albert, syn Wincentego i Anny z miasta Łańcuta, ur. 16 aprilis r. 1657

[152] Gaładziński Kazimierz, syn Alberta i Agnety, ur. 4 maja r. 1680

[153] Górski Andrzej, syn Andrzeja i Anny, ur. r. 1680 dnia 24 novembra

[154] Grzębski Piotr, syn gen. Szymona i Krystyny Grzębskich, ur. 25 iulii r. 1686

[155] Grzymała Zuzanna Marianna, córka gen. Alberti i Constantiae Grzymałów, ur. 9 augusta r. 1686

[156] Gruszecki Szymon, syn Jakuba i Zofii, ur. 24 octobra r. 1686

[157] Grabowski Stanisław, syn Walentego i Agnety, ur. 8 septembra r. 1699

[158] Gałęzowski Gregorius, syn Nicolai Gałęzowskiego i Anny Szczepanowskiej, ur. 8 marca r. 1718

[159] Grabińska Leonora Anna, córka gen. Simonis i Teresy Grabińskich, ur. 18 ianuarii r. 1735

[16o] [s. 21] Grabińska Marianna, córka gen. Simonis Grabiński i ... ${ }^{4}$, ur. 25 novembra r. 1743

[161] Grabowski Fabian Sebastian, syn Stefana i Maryjanny Grabowskich, ur. 22 ianuarii r. 1746

[162] Grabiński Szymon, syn gen. Simoni et Catharinae Grabińskich, ur. 21 octobra r. 1748

[163] Górecki Michael generosus z Katarzyną Ziebrowską ślub 14 maii r. 1742

[164] Gołębiowski Joannaes Mathias, syn Stanisława i Agnety, ur. 3 februarii r. 1768

[165] Gołębiowski Antoni, syn Michała i Maryjanny, ur. 11 iunii r. 1779

[166] Gołębiowski Adalbert, syn Stanisława i Agnety, ur. 17 aprilis r. 1774

[167] Gołębiowski Michał, syn Michała i Rozalii, ur. 11 septembris r. 1783

[168] Gębarzewski Joannes, filius gen. Joanni Gębarzewski venatori Nurensis de villa Błazow et Hedvigae, ur. 21 maii r. 1773

[169] [s. 22] Gębalski Josephus, filius gen. Gregorii Jacobi in Gembyczyn Grzymała Gębalski et Apoloniae de villa Czumów, ur. 28 octobris r. 1776

[170] Gruszecki Tomasz, syn Jana i Agnety, ur. 8 decembris r. 1786

4 Tak w rękopisie. 
[171] Gardysawski Sebestian, syn Adalberta i Rozalii, ur. 19 ianuarii r. 1789

[172] Gruszecki Marcin, syn Jana i Agnety ex parte Kusmirczak, ur. 6 novembris r. 1791

[173] Gołębiowski Andrzej, syn Laurentego i Anny Skibickiej, ur. 22 novembra r. 1795

[174] [s. 23] Hubowski Albert, syn Jana i Katarzyny z Lubyczy, ur. 28 marca r. 1683

[175] Heydyman Melchior generosus z Teofilą Czarnołuską wziął ślub 28 iunii r. 1721

[176] Humiński Gabriel, filius nob. Leopoldi et Annae Humińskich, ur. 30 maii r. 1763

[177] [s. 24] Jabłoński Sebastian, ojciec Jakub, matka Zuzanna, ur. 1 ianuarii r. 1650

[178] Jabłoński Marcin, syn Jana i Reginy, ur. 16 novembra r. 1657

[179] Jędrzejowski Michał, syn Jędrzejowskiego i Katarzyny, ur. 12 februarii r. 1674

[180] Janczyński Antoni, syn Stanisława i Anny, ur. 20 maii r. 1687

[181] Jakubowski Stanisław, syn Jakubowskiego, ur. 1 maja r. 1709

[182] Jankowski Marcin, syn Jana i Ewy Ochockiej de gente Cyganorum, ur. ultima octobris r. 1709

[183] Jaworski Stanisław, syn Antoniego i Doroty, ur. 11 maii r. 1774

[184] Janicki Michał, syn Jakuba i Maryjanny, ur. 16 septembris r. 1785

[185] Januszowski Jan, syn Tomasza i Agnety Komadowskiej, ur. 10 iulii r. 1786

[186] [s. 25] Korecki Sebastian, ojciec Stanisław, matka Regina ze wsi Bełżec, ur. 8 ianuarii r. 1650

[187] Kozłowski Stanisław, syn Alberta i Zofii ze wsi Podymszczyzny, ur. 4 iulii r. 1651

[188] Kęsicki Casimirus, syn gen. Damiani Joanni Kęsicki et Magdalenae de Florianów, ur. 8 iulii r. 1655

[189] Kozłowski Albert, syn Laurentego i Reginy z Lipska, ur. 20 marca r. 1657

[190] Kędzierski Andrzej, syn Jana i Ewy, ur. 20 novembra r. 1659

[191] Kłoczkowski Tomasz, syn Jana i Jadwigi, ur. 11 decembra r. 1674

[192] Kozłowski Jan, syn Sebastiana i Łucyi, ur. 28 maja r. 1681

[193] Kłoczkowski Błażej, syn Jana i Zofii, ur. 2 februarii r. 1686

[194] Kłoczkowski Józef, syn Jana i Zofii, ur. 13 maii r. 1688

[195] Krajewski Kazimierz, syn Piotra i Reginy, ur. 4 marca r. 1690

[196] [s. 26] Koszucki Jakub, syn nob. Gregorii Koszucki et Agneta de villae Chyże, ur. 10 iulii r. 1690

[197] Kozłowski Antoni, syn Stanisława i Agnety, ur. 17 maja r. 1691

[198] Kozłowski Jakub, syn Sebastiana i Katarzyny, ur. 13 iulii r. 1691

[199] Konopka Mathaeus, syn Tomasza i Zofii, ur. 16 septembris r. 1691

[200] Kasicki Franciszek, syn Stanisława i Łucyi, ur. 4 octobris r. 1691

[201] Kozłowski Antoni, syn Sebastiana i Katarzyny, ur. 12 maii r. 1695

[202] Koszucki Albert, syn Gregorii Koszuckiego i Agnety, ur. 21 aprilis r. 1697

[203] Kolbuszewski Marcin, syn Jana i Agnety, ur. 8 marca r. 1699 
[204] Kasicki Antoni, syn Stanisława Kasickiego consuli Florianoviensis i Katarzyny Bogackiej, ur. 17 augusta r. 1699

[205] [s. 27] Komnacki Kazimierz, syn Pawła Komnackiego i Maryjanny Szularzówny, ur. 2 marca r. 1702

[206] Kasicki Michał, syn Stanisława Kasickiego proconsuli Naroliensis i Katarzyny, ur. 7 septembris r. 1703

[207] Krupski Gregorius, syn Andrzeja i Anny, ur. 2 marca r. 1706

[208] Kozłowski Krzysztof, syn Pawła i Jadwigi, ur. 14 septembra r. 1707

[209] Kwiatkowski Franciszek Xawery, syn Jakuba i Katarzyny, ur. 1 decembra r. 1709

[210] Kulikowski Józef Antoni, syn gen. Casimiri Kulikowski i Wiktoryi, ur. 1 ianuarii r. 1715

[211] Kulikowski Laurenty Kajetan, filius gen. Casimiri Kulikowski i Wiktoryi in villa Chyże possesorum, ur. 16 augusta r. 1716

[212] Kulikowski Józef Antoni, syn gen. Casimiri Kulikowski i Wiktoryi, ur. 24 marca r. 1711

[213] [s. 28] Krzemieński Antoni, syn Jana i Zofii, ur. 3 iunii r. 1714

[214] Krzyszkiewicz Jakub, syn Alberta i Maryjanny Kozłowskiej, ur. 16 aprilis r. 1715

[215] Kwiatkowski Balcer, syn Jakuba i Katarzyny Kasprówny, ur. 10 ianuarii r. 1719

[216] Kamiński Teofil, syn gen. Francisci Kamińskiego i Katarzyny Trojanowskiej, ur. 26 marca r. 1720

[217] Krzyszkiewicz Sebastian, syn Alberta Krzyszkiewicza (sutoris) i Maryjanny Kozłowskiej, ur. 18 ianuarii r. 1721

[218] Kolbuszowski Laurenty, syn Marcina Kolbuszowskiego i Katarzyny Krajewskiej, ur. 5 iunii r. 1721

[219] Korabiowski Martinus, filius gen. Josephi et Maryjannae Korabiowskich, ur. 8 novembris r. 1723

[220] Korabiowski Constantinus, filius gen. Josephi et Mariannae Korabiowskich, ur. 14 februarii r. 1725

[221] Korabiowski Antoni, syn nob. Josephi Korabiewski et ... ${ }^{5}$, ur. r. 1730 dnia 27 augusta [222] [s. 29] Krzywiecki Józef, syn gen. Michaeli et Susannae Krzywieckich, ur. 21 marca r. 1734

[223] Krzywiecki Ignacy, syn gen. Michała i Zuzanny Krzywieckich, ur. 3 augusta r. 1735 [224] Krzywiecki Adam, syn gen. Michała i Zuzanny Krzywieckich, ur. 12 iulii r. 1738 [225] Kasperski Michał, syn Mathiae i Apolonii, ur. 11 novembra r. 1739

\footnotetext{
5 Tak w rękopisie.
} 
[226] Krzywiecki Tomasz, syn gen. Michaeli et Zuzannae Krzywieckich, ur. 10 decembra r. 1744

[227] Krzyszkiewicz Tomasz, syn Sebastiana i Jadwigi, ur. 8 decembra r. 1748

[228] Krzywiecki Franciscus, filius gen. Michaeli et Zuzannae Krzywieckich, ur. 1 marca r. 1753

[229] Krzeczkowski Błażej Antoni, syn Antoniego i Justyny, ur. 4 ianuarii r. 1755

[230] [s. 3o] Krzyszkiewicz Sebastian, syn Sebastiana i Katarzyny, ur. 18 ianuarii r. 1759

[231] Krzyszkiewicz Tomasz, syn Sebastiana i Katarzyny, ur. 7 decembra r. 1760

[232] Kawecki Mathias, syn Martini i Zofii, ur. 21 februarii r. 1762

[233] Kasicki Szymon Tadeusz, syn Michała advocati i Maryjanny Szumilakówny, ur. 31 octobris r. 1762

[234] Krzywiecki Michał generosus de villae Kadłubiska z Zuzanną Mogilnicką ślub 17 maii r. 1733

[235] Kasperski Mathias z Apolonią Kawecką ślub 9 augusta r. 1739

[236] Klisiewicz Jakub z Agnetą Laskowską ślub 13 augusta r. 1760

[237] Klisiewicz Andrzej, syn famati Jacobi i Agnety, ur. 14 novembris r. 1763

[238] Krzyszkiewicz Antoni, syn Sebastiana i Katarzyny, ur. 5 iunii r. 1765

[239] Kwieciński Casimirus, filius nob. Josephi Kwieciński et Annae, ur. 17 octobris r. 1765

[240] [s. 31] Kolbuszewski Kazimierz, syn Laurentego i Katarzyny de Piwuckie, ur. 27 marca r. 1766

[241] Kułakowski Tomasz, syn Szymona i Katarzyny, ur. 20 decembra r. 1766

[242] Krzyszkiewicz Józef, syn Sebastiana i Katarzyny, ur. 14 marca r. 1769

[243] Kierzśniowska Konstancyja Tekla, córka gen. Michaeli et Lidovicae de Węgleńskie Kierzśniowskich pincernae Laticzoviensis ${ }^{6}$, ur. 19 februarii r. 1771

[244] Kułakowski Jakub, syn Szymona i Katarzyny, ur. 29 iulii r. 1771

[245] Kozłowski Antoni, syn Adalberta i Teresy, ur. 26 maii r. 1773

[246] Kurowska Marianna Tekla, córka gen. Petri Ignatii et Rozaliae de Rościszewskie in Romanów Kurowsciorum, comisarum generalium Naroliensem, ur. 29 iunii r. 1773

[247] Kierzniowski Michał Alexander Felix Walery, filius magnifici domini Michaeli et Ludovicae Kierzniowskich oeconomorum Narolensem, ur. 30 septembris r. 1775

[248] [s. 32] Kurowski Leopoldus, filius gen. Ignatii et Rosaliae komisarstwa narolskich, ur. 30 decembra r. 1776

${ }^{6}$ W wykazie cześników latyczowskich żaden Kierśniowski, Kierzniowski (zob. nr 243) nie występuje, zob. E. Janas, W. Kłaczewski, J. Kurtyka, A. Sochacka, Urzędnicy podolscy XIV-XVIII wieku. Spisy, Kórnik 1998, s. 158-164. 
[249] Kolbuszowski Piotr, syn Laurentego i Katarzyny, ur. 29 iunii r. 1777

[250] Komadowski Jan, syn Tomasza i Maryjanny, ur. 21 maii r. 1778

[251] Komadowski Marcin, syn Tomasza i Maryjanny, ur. 12 novembra r. 1780

[252] Komadowski Laurenty, syn Tomasza i Maryjanny, ur. 4 augusta r. 1783

[253] Komadowski Kazimierz, syn Jana i Zofii Czuryłówny, ur. 1 marca r. 1786

[254] Kozłowski Casimirus Gregorius, syn nob. Ignatii et Elisabethae de Dramińskie Kozłowskich, ur. 8 marca r. 1786

[255] Komadowski Sebastian, syn Tomasza i Maryjanny, ur. 21 ianuarii r. 1787

[256] Komadowski Kazimierz, syn Antoniego i Maryjanny, ur. 28 februarii r. 1787

[257] Koszczakiewicz Tomasz, syn Mathiae i Christiny ex parte Karmazyn, ur. 7 marca r. 1787

[258] [s. 33] Kamiński Felix, syn Mathiae i Anny, ur. 1 iunii r. 1788

[259] Komadowski Antoni, syn Tomasza i Maryjanny, ur. 17 maii r. 1789

[260] [s. 34] Litwiński Jakub, syn Alberta Litwińskiego i Jadwigi z Florianowa, ur. 1 maii r. 1650

[261] Lipski Antoni, syn gen. Andrzeja de Lipsko Lipskiego i Maryjanny de Chamców, ur. 28 maja r. 1681

[262] Lipska Zofia, córka gen. Andrzeja Lipskiego i Maryjanny z Lipska, ur. 18 februarii r. 1684

[263] Lipski Kazimierz Józef, syn gen. Adaucti de Lipie Lipski, protunc tenutarii in oppido Lipsko et Agnetis, ur. 9 marca r. 1692

[264] Lewicki Józef, syn Jana i Reginy, ur. 17 marca r. 1693

[265] Lewicki Hiacynty, syn Jana i Reginy, ur. 21 augusta r. 1695

[266] Lewicki Laurenty, syn Jana i Reginy, ur. 6 augusta r. 1697

[267] Lipski Benedykt, syn gen. Józefa a Lipie Lipskiego thesaurarii Bełzensis i Annae Łętkowskiej, ur. 4 februarii r. 1687

[268] [s. 35] Lewicki Antoni, syn Jana i Reginy, ur. 14 maii r. 1707

[269] Lewicki Michał, syn Jana i Reginy, ur. 10 septembra r. 1709

[270] Lipska Rozalia Candida, córka ichm. Josephi de Lipe in Lipsko Lipskiego thesaurarii Bełzensis et Annae Łętkowska castellanidae Brzezinensis, ur. 12 novembris r. 1719 [271] Lubrzański Franciszek, syn Urbana i Maryjanny Przygodzińskiej, ur. 13 marca r. 1720 [272] Lipska Cecylia Elżbieta, córka illustrissimi gen. Josephi de Lipe in Lipsko Lipski thesaurarii Bełzensis et Annae Łętkowska castellanidae Brzezinensis ${ }^{7}$ [273] Lipska Justyna Praxeda, córka gen. Samuela Lipskiego i Klary, ur. 22 iulii r. 1723 [274] Lipski Marcin, syn gen. Antoniego Lipskiego i Zofii, ur. 16 novembra r. 1725

\footnotetext{
7 Daty w rękopisie brak.
} 
[275] Leszczyński Tomasz, syn Franciszka i Jadwigi, ur. 12 decembra r. 1728

[276] Lipski Konstanty Grzegorz, syn magnifici domini Antoni de Lipie Lipski et Sophiae Czeska, patrini fuerat Ignatius Albinowski et Antonius Czeski, ur. 17 marca r. 1729

[277] [s. 36] Leszczyński Laurenty, syn Franciszka i Jadwigi, ur. 10 augusta r. 1731

[278] Lisowski Adalbert, syn Adama i Maryjanny, ur. 14 marca r. 1744

[279] Lisowski Józef, syn nob. Józefa Lisowskiego i Maryjanny, ur. 23 marca r. 1749

[280] Lisowski Adalbert, filius nob. Josephi et Marianna Lisowskich, ur. 22 marca r. 1755

[281] Lubawski Wincenty Jan, filius gen. Martini et Elisabetha de Ponińskie Lubawskich de villae Lubau, ur. 23 marca r. 1761

[282] [s. 37] Łaszcz Katarzyna, córka gen. Casimiri Łaszcz i Konstancyi, ur. 28 novembra r. 1659

[283] Łagowski Mikołaj, syn Stanisława i Reginy, ur. r. 16608 decembra

[284] Łaszcz Georgius, filius gen. Casimiri Łaszcz et Constantiae, patrini fuerat gen.

Paulus Stanislaus Kęsicki vicerothmagister cohortis gen. Thomae Kliński rothmagistri S. R. M. et Theophila Mozgawska, ur. 18 aprila r. 1661

[285] Łaszcz Michael, filius gen. Casimiri Łaszcz et Constantiae de Wojutyn, ur. 24 decembra r. 1672

[286] Łaszcz Joannes Stephanus, filius gen. ac magnifici Casimiri Łaszcz Nieledewski et Constantiae de Woiutyn Łaszczów, patrini fuerat Andreas Lipski et Ursula consors Pauli Stanislai Kęsicki pincernae Novogrodensis, ur. 21 ianuarii r. 1675

[287] Łotecki Stanisław Antoni, syn gen. Hieronima Łoteckiego i Maryjanny, ur. 11 maja r. 1687

[288] [s. 38] Łotecki Jan Andrzej, syn gen. Hieronimi i Marianny Łoteckich, ur. 19 maii r. 1688

[289] Łubkowski Kazimierz Marcin, syn gen. Michała Łubkowskiego i Barbary, ur. 10 ianuarii r. 1692

[290] Łowiecki Laurenty, syn Sebestiana i Agnety, ur. 7 augusta r. 1701

[291] Łukowski Adam, syn Alberta i Ewy, ur. 28 septembra r. 1709

[292] Łagowski Józef, syn Stanisława z Huty Lubyckiej i Maryjanny, ur. 22 marca r. 1723

[293] Łagowski Sebastian, syn Stanisława i Maryjanny, ur. 6 ianuarii r. 1725

[294] Łukowski Mathias, syn Hieronima i Anny, ur. 22 februarii r. 1761

[295] Łysakowski Marcin, syn Łukasza i Jadwigi, ur. 1 novembris r. 1767

[296] Łysakowski Jakub, syn Łukasza i Jadwigi, ur. 29 iulii r. 1771

[297] Łysakowski Christophorus, syn Łukasza i Jadwigi, ur. 8 septembris r. 1776

[298] [s. 39] Makowski Gregorius, syn Andrzeja i Teresy, ur. 10 marca r. 1680

[299] Makowski Michał, syn Andrzeja i Tańki, ur. 1 septembra r. 1686

[300] Mosiewicz Marianna, filia nob. Martini et Brigitae Mosiewicz, ur. 27 aprilis r. 1692 
[301] Michalski Antoni, syn Szymona i Anny, ur. 10 iunii r. 1711

[302] Malinowski Michał, syn Stanisława i Anny, ur. 2 septembris r. 1714

[303] Michałowski Szymon, syn Michała i Zofii, ur. 28 octobra r. 1721

[304] Mroczkowski Mathias, syn nob. Sebastiani et Sophiae Mroczkowskich, ur. 24 februarii r. 1725

[305] Mogilnicka Rozalia Antonina, córka magnifici Akexandri et Mariannae Mogilnickich venatori Żydaczoviensis, ur. 16 augusta r. 1725

[306] Michałowski Sebestian, syn Michała i Zofii, ur. 14 ianuarii r. 1726

[307] [s. 40] Mogilnicki Franciszek Xavery, syn magnifici Alexandra i Maryjanny Mogilnickich venatori Żydaczoviensis de villa Chyże, ur. 17 decembra r. 1727

[308] Michalski Tomasz, syn Józefa i Zofii, ur. 1 decembra r. 1730

[309] Mroczkowski Stanisław, syn Sebestiana i Zofii, ur. 4 maja r. 1732

[310] Magnuski Nicolaus, syn Szymona i Maryjanny, ur. 6 decembra r. 1733

[311] Mogilnicki Ignacy Łukasz, syn magnifici Franciszka i Katarzyny Mogilnickich subpalatini Stężycensis, ur. 31 octobra r. 1734

[312] Mroczkowski Józef, syn Sebestiana i Zofii, ur. 6 marca r. 1735

[313] Mogilnicki Jan Alexander, filius gen. Francisci Mogilnicki subpalatini Stężycensis i Katarzyny, ur. 10 iulii r. 1737

[314] Mogilnicki Antoni Bazyli, syn gen. Francisci Mogilnickiego i Katarzyny, ur. 13 iulii r. 1741

[315] [s. 41] Mogilnicki Alexander Błażej, syn gen. Joanni et Konstancja Mogilnickich, ur. 5 februarii r. 1743

[316] Mogilnicki Stanisław Józef, filius gen. Francisci Mogilnicki subpalatini Stężycensis i Katarzyny, ur. 10 maii r. 1744

[317] Mogilnicki Paweł, syn gen. Mogilnickiego ${ }^{8}$ i Joanny, ur. 9 ianuarii r. 1751

[318] Makowski Antoni, syn Pawła i Katarzyny, ur. 23 maii r. 1752

[319] Mogilnicki Tomasz, syn gen. Jana i Konstancji Mogilnickich, ur. 12 decembra r. 1753 [320] Makowski Antoni, syn Pawła i Katarzyny, ur. 3 marca r. 1754

[321] Mogilnicki Jacobus, filius gen. Joanni et Constantiae Mogilnickich, ur. 25 iulii r. 1755

[322] Makowski Tomasz, syn Pawła i Katarzyny, ur. 7 decembra r. 1755

[323] Makowski Jan, syn Pawła i Katarzyny, ur. 12 iunii r. 1757

[324] [s. 42] Mogilnicka Katarzyna, córka gen. Ignacego i Maryjanny Mogilnickich, ur. 23 novembris r. 1758

[325] Mogilnicki Klemens Ignacy, filius gen. Joanni et Konstantiae Mogilnickich, ur. 10 decembra r. 1759

\footnotetext{
$8 \quad$ Imienia $w$ rękopisie brak.
} 
[326] Mogilnicki Łukasz Antoni Józef, filius gen. Ignatii Mogilnicki et Mariannae, ur. 15 octobra r. 1760

[327] Małaszewski Jan, filius nob. Thomae et Annae Małaszewskich, ur. 24 octobris r. 1762 [328] Mogilnicki Joannes Alexander, filius gen. Francisci Mogilnicki subpalatini Stężycensis, ur. 21 iulii r. $1737^{9}$

[329] Mogilnicki Joannes generosus z Konstancyją Tymińską ślub 26 novembris r. 1735 [330] Makowski Paweł z Maryjanną Mulakówną ślub 22 ianuarii r. 1747

[331] Makowski Joachim Krzysztof, syn Krzysztofa i Katarzyny, ur. 7 septembris r. 1763 [332] [s. 43] Makowski Mathias, syn Krzysztofa i Katarzyny, ur. 15 februarii r. 1766 [333] Makowski Alexy Jakub, syn Krzysztofa i Katarzyny, ur. 17 iulii r. 1768 [334] Makowski Piotr Paweł, syn Krzysztofa i Katarzyny, ur. 28 iunii r. 1771 [335] Malicki Jakobus, filius gen. Simoni et Catharinae Malickich, ur. 4 iulii r. 1771 [336] Maniewski Adalbert, syn Stanisława i Zofii, ur. 11 aprilis r. 1774 [337] Majewski Adalbert, syn Stanisława i Zofii, ur. 15 maja r. 1775 [338] Majewski Michał, syn Stanisława pictoris et Katarzyny, ur. 28 septembris r. 1777 [339] Majewski Franciszek Antoni, syn Stanisława Majewskiego i Katarzyny, ur. 17 septembris r. 1778

[340] Myszkowski Kazimierz, syn Jana i Zofii, ur. 13 februarii r. 1780

[341] Makowski Jan, syn Stanisława i Łucji, ur. 24 iunii r. 1785

[342] Mulacki Marcin, syn Adalberta i Katarzyny, ur. 4 octobra r. 1785

[343] [s. 44] Malinowski Sebastian, syn Jana i Anastazji, ur. 21 ianuarii r. 1787

[344] Malinowski Błażej, syn Jana i Anastazji Kosakówny, ur. 9 februarii r. 1788

[345] [s. 45] Nawrotowski Andreas, syn Jakuba i Jadwigi z Florianowa, ur. 18 novembra r. 1653

[346] Niemirski Jan, syn Alberta i Elżbiety, ur. 8 ianuarii r. 1658

[347] Nawrotowski Szymon, syn Jakuba i Jadwigi, ur. 15 februarii r. 1660

[348] Niegardowski Jakub, syn Jana i Katarzyny, ur. 1 iulii r. 1678

[349] Nartowski Ignacy Casimirus, syn gen. Joanni Nartowski i Gryzeldy, ur. 2 februarii r. 1687

[350] Niegardowski Franciscus, syn Jana i Katarzyny, ur. 4 octobra r. 1689

[351] Nawrocki Kazimierz, syn Kazimierza i Anny, ur. 2 marca r. 1692

[352] Nawrocki Jan Duklian, syn Kazimierza i Anny, ur. 30 octobris r. 1696

[353] Niegardowski Albert, syn Stanisława i Agnety, ur. 8 aprila r. 1704

[354] Niegardowski Sebastian, syn Hiacyntego i Heleny, ur. 2 ianuarii r. 1705

[355] [s. 46] Niegardowski Błażej, syn Stanisława i Agnety, ur. 2 februarii r. 1706

9 Zapewne tożsamy z Janem Aleksandrem (nr 313), gdzie jest jednak nieco inna data urodzin. 
[356] Nartowski Justyn Alexander, syn gen. Stanislai Nartowski i Reginy, ur. 11 octobris r. 1709

[357] Niegardowski Kazimierz, syn Stanisława i Agnety, ur. 3 marca r. 1709

[358] Niegardowski Albert, syn Hiacyntego i Agnety, ur. 3 aprilis r. 1710

[359] Nartowski Christophorus, syn gen. Stanislai Nartowski i Reginy, ur. ultima martii r. 1711

[360] Nartowski Antoni, syn gen. Stanislai Nartowski et Regina, ur. 26 iunii r. 1714

[361] Nartowski Andrzej, syn nob. Franciszka Nartowskiego i Ewy, ur. 3 decembra r. 1714 [362] Nartowski Jan, syn gen. Stanislai Nartowski i Reginy Piątkowskiej, ur. 13 maja r. 1717 [363] Niegardowski Dominik, syn Stanisława i Agnety Łoykówny, ur. 8 augusta r. 1718 [364] [s. 47] Nartowski Albert, syn gen. Stanisława Nartowskiego i Reginy Piątkowskiej, ur. 28 marca r. 1720

[365] Nartowski Kazimierz, syn gen. Stanislai Nartowskiego i Reginy, ur. 4 marca r. 1704 [366] Nartowski Łukasz, syn gen. Franciszka Nartowskiego i Ewy, ur. 25 octobra r. 1724 [367] Niegardowski Adalbert, syn Antoniego i Maryjanny, ur. 15 kwietnia r. 1729

[368] Nartowski Jan Antoni, syn gen. Josephi et Ludovicae Nartowskich, ur. 14 iunii r. 1730 [369] Niegardowski Walenty, syn Antoniego i Maryjanny, ur. 6 februarii r. 1738 [370] Niegardowski Marcin, syn Sebastiana i Doroty, ur. 3 novembris r. 1739 [371] Niegardowski Tomasz, syn Sebastiana i Doroty, ur. 6 decembra r. 1744 [372] Nartowski Gaspar Józef, filius gen. Nicolai et Annae Nartowskich, ur. 8 ianuarii r. 1747

[373] Niegardowski Sebastian, syn Adalberta i Maryjanny, ur. 15 ianuarii r. 1747

[374] [s. 48] Nartowski Ludwik, syn nob. Józefa Nartowskiego i Katarzyny, ur. 27 augusta r. 1749

[375] Nartowski Adalbert Jakub, syn gen. Josephi et Catharinae Nartowskich, ur. 28 kwietnia r. 1754

[376] Niegardowski Sebestian, syn Adalberta i Jadwigi, ur. 8 stycznia r. 1756

[377] Niegardowski Sylwester Sebestian, syn Adalberta i Jadwigi, ur. 30 decembra r. 1762 [378] Nartowski Josephus generosus z Katarzyną Bestkowską ślub 29 ianuarii r. 1747 [379] Niegardowski Joachim Mikołaj, syn Tomasza i Agnety, ur. 4 septembris r. 1763 [380] Niegardowski Joannes a Cruce Andreas, syn Mikołaja i Maryjanny Niegardowskich, ur. 25 novembra r. 1770

[381] Niegardowski Laurenty, syn Mikołaja i Maryjanny, ur. 12 augusta r. 1781

[382] [s. 49] Niegardowski Gregorius Josephus, syn Mikołaja i Maryjanny, ur. 17 marca r. 1784

[383] Niegardowski Andreas, syn Stanisława i Zofii, ur. 27 novembris r. 1785 [384] Niegardowski Jakub Krzysztof, syn Mikołaja i Maryjanny, ur. 3 maja r. 1787 
[385] Nowacki Felix Hilary, filius gen. Stephani Nowacki profesora szkoły normalnej w Narolu i Zofii ex parte Łepkowskiej, ur. 15 ianuarii r. 1789

[386] [s. 5o] Olszowski Albert, syn Andrzeja i Zuzanny ze wsi Krupiec, ur. 30 marca r. 1656

[387] Osmólski Szymon, syn Alberta i Mariny, ur. 20 octobra r. 1669

[388] Ostrowski Albert, syn Marcina i Katarzyny, ur. 20 marca 1674

[389] Osmólski Albert, syn Alberta i Barbary, ur. 10 aprila r. 1674

[390] Osmólski Albert, syn Alberta i Barbary, ur. 26 aprila r. 1675

[391] Ostrowski Marcin, syn Marcina i Marianny, ur. 11 novembra r. 1685

[392] Ostrowski Jakub, syn Marcina i Marianny, ur. 10 iulii r. 1687

[393] Ostrowski Mathias, syn Marcina i Marianny, ur. 16 februarii r. 1690

[394] Ostrowski Michał, syn Jana i Jadwigi, ur. 1 octobris r. 1694

[395] Orłowski Antoni generosus z Konstancyją Jagiełowiczówną wziął ślub 6 februarii r. 1725

[396] Ostrowski Albert z Anną Wiechmówną wziął ślub 6 februarii r. 1725

[397] Ostrowski Albert, syn Mikołaja i Anny, ur. 22 marca r. 1707

[398] [s. 51] Orlikowski Tomasz, syn Bazylego i Katarzyny, ur. 1 ianuarii r. 1710

[399] Orlikowski Laurenty, syn Bazylego i Katarzyny, ur. 10 augusta r. 1715

[40o] Olszański Stanisław, syn Szymona i Jadwigi Małdrzykówny, ur. 15 maii r. 1718

[401] Ostrowski Walenty, syn Franciszka i Agnety, ur. 7 februarii r. 1723

[402] Orłowski Józef Franciszek, syn gen. Antoni Orłowskiego i Konstancyi, ur. 12 octo-

bra r. 1726

[403] Ostrowski Jakub, syn Franciszka i Agnety, ur. 22 iulii r. 1733

[404] Orłowski Błażej, syn Teodora i Maryjanny, ur. 27 ianuarii r. 1760

[405] Olewiński Tadeusz Marcin, syn Michała i Maryjanny, ur. 24 octobris r. 1762

[406] Okorski Franciscus generosus, administrator villae Chociulub z Faustyną Chrusz-

czewską ślub 8 ianuarii r. 1747

[407] [s. 52] Ostrowski Mathias, syn Jakuba i Reginy, ur. 14 februarii r. 1762

[408] Ostrowski Sebestian, syn Jakuba i Reginy, ur. 19 ianuarii r. 1766

[409] Ogromski Laurenty, syn Jakuba i Anny, ur. 28 iulii r. 1771

[410] Ostrowski Jan Baptysta, syn Mathiae i Maryjanny ex parte Kolbuszewska, ur. 22 iunii r. 1788

[411] Ostrowski Adam Adalbert, syn Mathiae i Maryjanny, ur. 1 aprila r. 1791

[412] Ostrowski Józef, syn Mathiae i Maryjanny, ur. 22 novembra r. 1794

[413] Ostrowski Franciszek, filius nob. Mathiae Ostrowski et Mariannae, ur. 1 octobra r. 1796

[414] [s. 53] Pogorzelski Mathias, syn Sebestiana Pogorzelskiego proconsuli Florianoviensis i Reginy, ur. 24 februarii r. 1650 
[415] Pogorzelski Jakub, syn Mathiae i Reginy, ur. 4 iulii r. 1671

[416] Pogorzelski Pawel, syn Szymona i Doroty, ur. 22 ianuarii r. 1679

[417] Pajewski Józef Alexander, syn nob. Nicolai Pajewski i Marianny Głuszkowskiej, ur. 20 marca r. 1690

[418] Piątkowski Gregorius, syn Józefa i Agnety, ur. 7 marca r. 1728

[419] Przestrzelska Marianna, córka gen. Ignacego i Zofii Przestrzelskich, ur. 31 marca r. 1763

[420] Podgurski Jakub z Reginą Sokalską ślub 25 ianuarii r. 1739

[421] Pluciński Antoni, syn Tomasza i Apolonii, ur. 1 iunii r. 1767

[422] [s. 54] Potocki Józef, filius gen. Stanisława i Katarzyny Potockich ekonomów i burgrabiów narolskich, ur. 15 februarii r. 1777

[423] Pluciński Franciszek, syn Mikołaja i Katarzyny, ur. 2 maii r. 1791

[424] Pluciński Marcin, syn Mikołaja i Katarzyny Łoykówny, ur. 16 octobra r. 1796

[425] [s. 55] Rachański Tomasz, syn Jana i Reginy z Florianowa, ur. 13 decembris r. 1654 [426] Rachański Jan, syn Jana i Reginy z Florianowa, ur. r. 1656 dnia 25 maii

[427] Rozański Jan, syn Walentego i Heleny, ur. ultima martii r. 1700

[428] Rozański Błażej, syn Walentego i Heleny, ur. ultima ianuarii r. 1704

[429] Rogowski Albert, syn Pawła i Zofii, ur. 6 aprila r. 1710

[430] Rozwadowski Bartłomiej, syn nob. domini Simoni Rozwadowski i Maryjanny, ur. 15 augusta r. 1723

[431] Radecki Paulus Ignatius, syn generosi Feliciis et Mariannae Radeckich, ur. 5 februarii r. 1725

[432] Rayska Katarzyna, córka generosi Sebastiani Rayski et Agnetae, ur. r. 174411 novembra

[433] Rykowski Antoni, syn generosi Andreae et Apoloniae Rykowskich, ur. 30 maii r. 1745 [434] [s. 56] Radecki Sebestian Antoni, syn gen. Francisci et Mariannae Radeckich, ur. 17 ianuarii r. 1751

[435] Rayski Tomasz, syn Adalberta i Anny Rayskich, ur. 19 decembra r. 1755

[436] Rużycki Tomasz, syn Andrzeja i Katarzyny, ur. 19 decembra r. 1756

[437] Rogoziński Paulus nobilis, militem, z Katarzyną Nartowską ślub 7 februarii r. 1730

[438] Rykowski Antonius generosus z Apolonią Mandecką ślub 2 augusta r. 1744

[439] Radecki Franciscus generosus de Potelicz z Maryjanną Nartowską ślub 27 augusta r. 1747

[440] Rużycki Kazimierz, syn Andrzeja i Ewy, ur. 5 marca r. 1764

[441] Romański Jakub, syn Jakuba i Krystyny, ur. 25 marca r. 1767

[442] Rozański Jakub, syn Jakuba i Agnety, ur. 18 iulii r. 1768

[443] [s. 57] Ranizeski Marcin, syn Łukasza i Agnety, ur. 30 octobra r. 1782 
[444] Rużycki Marcin, syn Jana i Salomei ex parte Osadzińskiej, ur. 18 octobris r. 1792

[445] [s. 58] Skorodyński Andreas, syn Mathiae i Mariny z Florianowa, ur. 25 novembra r. 1654

[446] Sokołowski Christophorus, syn Stefana Sokołowskiego i Anny z Florianowa, ur. 14 septembra r. 1655

[447] Szczeptowski Mathias, syn Hieronima i Mariny z Niemirowa, ur. 25 februarii r. 1657

[448] Sochanowski Stanisławus, filius gen. Jacobi Sochanowski et Agnetis, ur. 11 maii r. 1659

[449] Solski Michał, syn Alberta i Barbary, ur. 10 octobra r. 1659

[450] Sokołowski Marcin, syn Pawła sutoris i Maryjanny, ur. 30 octobris r. 1673

[451] Stanisławski Stanisław, syn Alberta Stanisławskiego z Dynisk i Zofii, ur. 18 aprilis r. 1678

[452] Szatkowski Łukasz, syn Jana i Katarzyny, ur. 16 octobris r. 1678

[453] Staszyński Albert, syn Walentego Staszyńskiego Rozanieckiego i Marianny, ur. 7 aprilis r. 1680

[454] Świderski Łukasz, syn Mikołaja i Katarzyny, ur. 13 septembris r. 1680

[455] [s. 59] Skotnicki Jan, syn Laurentego i Katarzyny, ur. 22 decembra r. 1683

[456] Skotnicki Kazimierz, syn Gregorii i Katarzyny, ur. 18 februarii r. 1684

[457] Sokołowski Jan, syn Pawła i Maryny, ur. 28 maja r. 1684

[458] Silnicka Zofia, córka gen. Jana [Stefana] i Katarzyny Silnickich, dziedziców Florianowa, ur. in Crustinum [?] r. 1682

[459] Silnicki Rosa Joannes, infant gen. Jana Stefana Silnickiego i Katarzyny dziedziców Florianowa, ur. 9 septembri r. 1685

[460] Sawiński Walenty, syn Alberta i Heleny, ur. 14 februarii r. 1688

[461] Silnicka Joanna Brygida, córka Jana Stefana i Katarzyny Teresy de Lipiny Drużbicówny. Trzymali do chrztu świętego Jan Stanisław de Lipiny Drużbic venator Horodliensis, Alexander de Tuczapy Łaszcz capitaneus Grabovecensis cum Theophilae Konstantiae Drużbicówna et Anna Lesiecka, ur. 24 iunii r. 1688

[462] Śliwiński Albert, syn Alberta i Heleny, ur. 20 aprilis r. 1690

[463] [s. 6o] Szczepański Andrzej, syn Stefana i Agnety, ur. 2 novembra r. 1690

[464] Silnicki Michał, syn gen. Jana Silnickiego vexiliferi Podoliae, capitaneum Bucznoviensis et Catharinae, ur. 26 decembra r. 1690

[465] Stawska Anna, córka gen. Alexandri Stawski et Joannae, ur. 7 augusta r. 1691

[466] Silnicka Wiktoria Bogumiła, córka gen. Jana Stefana Silnickiego vexiliferi Podoliensis i Katarzyny Teresy de Lipiny Drużbicówny, ur. 15 septembra r. 1692

[467] Sowiński Jan, syn gen. Michaeli et Euphrosinae Sowińskich, ur. 8 marca r. 1693

[468] Sawicki Michał, syn Szymona i Krystyny z Tomaszowa, ur. 17 septembris r. 1694 
[469] Solski Mikołaj Franciszek, syn gen. Martini et Barbarae Solskich, ur. 8 marca r. 1699 [470] [s. 61] Sobierajski Samuel Paweł, syn nob. Casimiri Sobierajski i Marianny, ur. 6 marca r. 1705

[471] Sobierajski Samuel generosus z Teresą Nartowską wziął ślub 1 februarii r. 1722 [472] Słociński Laurenty, syn Hiacyntego i Reginy, ur. 11 augusta r. 1710 [473] Styrpeko Ignacy, syn gen. Stanislai Styrpeko i Anny, ur. 3 septembris r. 1710 [474] Sokulski Dionizy, syn Laurentego Sokulskiego i Zofii Banasiówny, ur. 10 octobra r. 1720

[475] Sokołowski Andrzej, syn Jana i Maryjanny, ur. 2 decembra r. 1721

[476] Szarzyński Antoni, syn Jana i Katarzyny, ur. 28 maja r. 1726

[477] Szymański Bartłomiej, syn Krzysztofa i Katarzyny, ur. 20 augusta r. 1726 [478] Szulc Michał Tomasz, filius gen. Martini et Annae Szulc, natum 18 septembra, chrzczony 28 septembra r. 1734

[479] [s. 62] Szymański Marcin, syn Krzysztofa i Katarzyny, ur. 7 novembra r. 1734 [480] Szuchtan Rola Jakobus, filius gen. Martini in Domaniny et Jasiory Rola Szuchtan et Annae, ur. 5 octobris r. 1742

[481] Suchodolska Barbara, córka gen. Martini Suchodolski i Rozalii, ur. 8 decembris r. 1750

[482] Skibiński Stefan, syn Andrzeja i Katarzyny, ur. 27 decembra r. 1755

[483] Skulski ${ }^{10}$ Mathaeus, syn Bartłomieja i Marianny, ur. 5 septembra r. 1756

[484] Skulski Laurenty, syn Bartłomieja i Maryjanny, ur. 5 augusta r. 1759

[485] Szulc Martinus nobilis z Anną Krasowską ślub 1o februarii r. 1732

[486] Sroczkowski Andreas generosus, administrator Lipscensis z Agnetą Winiarską ślub 18 ianuarii r. 1733

[487] Suchodolski Martinus generosus z Rozalią Nartowską ślub 3 februarii r. 1750

[488] Szczudłowski Mikołaj, syn Jana i Ewy, ur. 2 decembris r. 1779

[489] [s. 63] Świątoniewski Bartłomiej, syn Stanisława i Zofii, ur. 15 augusta r. 1780

[49o] Szadowski Jan, syn Józefa i Rozalii, ur. 13 maii r. 1782

[491] Śmietanowicz Agneta Marina, córka gen. Ignatii Josephi Śmietanowicz et Magda-

lenae de Kasperska, comisariorum Narolensem, ur. 28 ianuarii r. 1783

[492] Szajewski Gregorius Antonius, syn Sebastiana i Agnety, ur. 25 maii r. 1783

[493] Skulski Ignacy Piotr, syn Antoniego i Zofii, ur. 27 iunii r. 1784

[494] Skowroński Kazimierz, syn Antoniego i Anny, ur. 22 ianuarii r. 1785

[495] Świątoniewski Błażej, syn Michała i Katarzyny, ur. 4 ianuarii r. 1785 [496] Sędecki Stanisław, syn Tomasza i Maryjanny, ur. 20 novembris r. 1785

10 Być może błędny odczyt, zamiast popularnego w Narolu nazwiska: Skalski. 
[497] Szydłowski Franciscus, syn Sebastiana i Zofii, ur. 15 septembris r. 1786

[498] [s. 64] Skibiński Marcin, syn Jakuba i Reginy, ur. 3 octobris r. 1786

[499] Stankiewicz Stanisław, syn Laurentego i Katarzyny, ur. 16 novembra r. 1786

[500] Szajewski Sebestian, syn Sebestiana i Agnety, ur. 20 februarii r. 1788

[501] Skalski Mathaeus, syn Laurentego i Hedwigi, ur. 19 septembris r. 1789

[502] Skibiński Józef minor, Gabriel maior, synowie gen. Joanni Skibiński et Annae ex parte Woyda, ur. r. 1792 dnia 26 marca

[503] Skibiński Jakób, syn Adalberta i Katarzyny, ur. 29 aprilis r. 1792

[504] Skalski Antoni, syn Laurentego i Hedwigi, ur. 9 ianuarii r. 1793

[505] [s. 65] Trojański Sebastianus, syn Błażeja i Zofii z Florianowa, ur. 23 ianuarii r. 1654

[506] Topornicki Jan, syn Jana i Katarzyny z Florianowa, ur. 6 maja r. 1655

[507] Tomaszowski Andrzej, syn Szymona i Maryjanny, ur. 3 decembra r. 1658

[508] Trawiński Gregorius, syn Jana i Jadwigi, ur. 8 marca r. 1693

[509] Toporowski Antoni, syn Stanisława i Konstancyi, ur. 25 maii r. 1710

[510] Trzeciecki Kajetan Faustyn, syn nob. Alberti Trzeciecki i Magdaleny, ur. 17 octobra r. 1711

[511] Tomaszewski Sebestian, syn nob. domini Antonii et Catharinae Tomaszewskich, ur. 16 ianuarii r. 1724

[512] Tymowski Piotr Paweł, syn gen. Josephi et Bogumiłae Tymowskich, ur. 29 iunii r. 1729

[513] Trząkowski Antonius Xistus, syn gen. Josephi Trząkowski kamerdynum ill, m. palatini Pomeraniae i Franciszki, ur. 25 aprilis r. 1783

[514] [s. 66] Trząkowski Marcin Dominik, syn Józefa i Franciszki, ur. 21 novembris r. 1784

[515] Trząkowski Franciszek Michał, syn Józefa Trząkowskiego i Franciszki, ur. 20 septembra r. 1786

[516] [s. 67] Ujazdowska Salomeia, córka gen. Michaeli Ujazdowski i Katarzyny Wyzdżanki de villa Chyże, ur. 21 aprilis r. 1718

[517] [s. 68] Wysocki Kazimierz, syn Stanisława i Zofii z Florianowa, ur. 8 marca r. 1652

[518] Wąż Felicianus, syn gen. domini Wąż i Anny, ur. 7 octobris r. 1669

[519] Wojszewska Brygida Teresa, córka gen. Walentini et Constantiae Wojszewskich, ur. 30 septembra r. 1688

[520] Wilczyński Antoni, syn Waleriana i Anny, ur. 8 maii r. 1695

[521] Wolski Andrzej, syn Jakuba i Anastazyi, ur. 24 novembra r. 1709

[522] Wigant Ludwik, syn nob. Ertmana Wigant i Konstancji, ur. 4 novembra r. 1725

[523] Winiarski Jacobus, filius gen. Adalberti et Catharinae Winiarskich, ur. 25 iulii r. 1748

[524] Winiarski Marcin, filius gen. Adalberti et Catharinae Winiarskich, ur. 8 novembris r. 1750 
[525] Winiarski Fabian Sebastian, syn gen. Adalberti i Katarzyny Winiarskich, ur. 28 ianuarii r. 1753

[526] [s. 69] Wicijowski Antoni, syn Adama i Maryjanny, ur. 29 maii r. 1754

[527] Wicijowski Gaspar, syn Błażeja i Teresy, ur. 3 ianuarii r. 1760

[528] Winiarski Adalbertus generosus, administrator villae Lipie z Katarzyną Goniprowską ślub 29 augusta r. 1745

[529] [s. 70] Zieleński Stanisław, syn Alberta i Martianny z Huty Susieckiej, ur. 27 ianuarii r. 1655

[530] Zieleński Franciszek, syn Adama i Katarzyny z Huty Susieckiej, ur. octobris ${ }^{11}$ r. 1656

[531] Zaremba Tomasz, syn Franciszka i Anny, ur. 11 decembra r. 1658

[532] Załuski Andrzej, syn Łukasza i Jadwigi, ur. ultima novembris r. 1682

[533] Zieliński Laurenty, syn Marcina i Agnety, ur. 26 iulii r. 1685

[534] Żukowski Józef, syn Gaspara i Zofii, ur. 18 marca r. 1685

[535] Żorawski Ignacy, syn Gregorii i Agnetis, ur. 26 ianuarii r. 1687

[536] Żurakowski ${ }^{12}$ Marcin, syn Gaspara i Anny, ur. 4 novembra r. 1687

[537] Zaleski Tomasz, syn Tomasza i Katarzyny, ur. 21 decembra r. 1687

[538] Zieleński Paweł, syn Jana i Agnety, ur. 2 ianuarii r. 1689

[539] Zbiejowski Jan, syn Alberta i Mariny, ur. 1 ianuarii r. 1691

[540] Zieleński Laurenty, syn Szymona i Zofii, ur. 5 augusta r. 1691

[541] Żurawski Albert, syn Gregorii i Agnety, ur. 1 aprila r. 1696

[542] Żołyński Błażej, syn Mathiae i Anny, ur. 1 februarii r. 1697

[543] Załuski Michał, syn Alberta i Jadwigi, ur. 14 septembra r. 1698

[544] Zubrzycki Bartłomiej, syn Jana i Reginy, ur. 12 augusta r. 1701

[545] Żołyński Stefan, syn Franciszka i Agnety Cichoniówny, ur. 24 decembra r. 1719

[546] Zawadzki Jan, syn Antoniego i Anny, ur. 19 iunii r. 1781

11 Daty dziennej w rękopisie brak.

12 W rękopisie AGAD, Czoł. 508: Żuczkowski. 


\section{Indeks osób}

Albinowski Ignacy 276

Axan Marianna Agnieszka 1

Axan Piotr 1, 2

Axan Salomea Katarzyna 2

Axan z Krzynickich Agnieszka 1, 2

Babecka Eufrozyna 40

Babecki Antoni Marcin Kajetan 40

Babecki Kajetan, gubernator narolski 40

Banaś zob. Sokulska z Banasiów

Baranowska Regina 8, 9

Baranowski Grzegorz 9

Baranowski Jan 8, 9

Baranowski Maciej 8

Bestkowska zob. Nartowska

z Bestkowskich

Białobocka Zofia 4

Białobocki Aleksander 4

Białobocki Sebastian 4

Bielecka Elżbieta 3, 5

Bielecka Ewa 34, 35, 37

Bielecka Jadwiga 36

Bielecka Katarzyna 24

Bielecka Katarzyna 26, 29

Bielecka Klara z Drozdów 28, 30, 31

Bielecka Marianna 32

Bielecka Marianna 43

Bielecka Marianna 50

Bielecka Regina 18, 20

Bielecka z Mulaków Marianna 49, 51, 52, 54, 55

Bielecki Adam 28, 30, 31

Bielecki Adam 30

Bielecki Adam 34, 35, 37

Bielecki Andrzej 26, 29

Bielecki Andrzej 34

Bielecki Andrzej 51

Bielecki Bartłomiej 43

Bielecki Bartłomiej 50

Bielecki Bernard 36
Bielecki Błażej 49, 51, 52, 54, 55

Bielecki Franciszek 16

Bielecki Hieronim 55

Bielecki Jakub 26

Bielecki Jakub 52

Bielecki Jan 3

Bielecki Jan 31

Bielecki Jan 54

Bielecki Krzysztof 43

Bielecki Krzysztof Michał 49

Bielecki Laurenty 3, 5

Bielecki Maciej Józef 50

Bielecki Marcin 20

Bielecki Michał 28

Bielecki Mikołaj 18, 20, 24

Bielecki Mikołaj 24

Bielecki Paweł 32

Bielecki Piotr 5

Bielecki Szymon 16

Bielecki Szymon 35

Bielecki Tomasz 18

Bielecki Tomasz 29

Bielecki Tomasz 36

Bielecki Tomasz 45

Bielecki Walenty 37

Bielecki Wojciech 24

Bielecki Wojciech 32

Bielska Zofia 10

Bielski Andrzej 10

Bielski Maciej 10

Blamowicz Anastazja 38

Blamowicz Mikołaj 38

Blamowicz Szymon 38

Blamowska Marianna 33

Blamowski Maciej 33

Blamowski Szymon 33

Bogacka zob. Kasicka z Bogackich

Bogusz Franciszek 14

Bogusz Jakub 14, 15

Bogusz Maryna 14, 15 


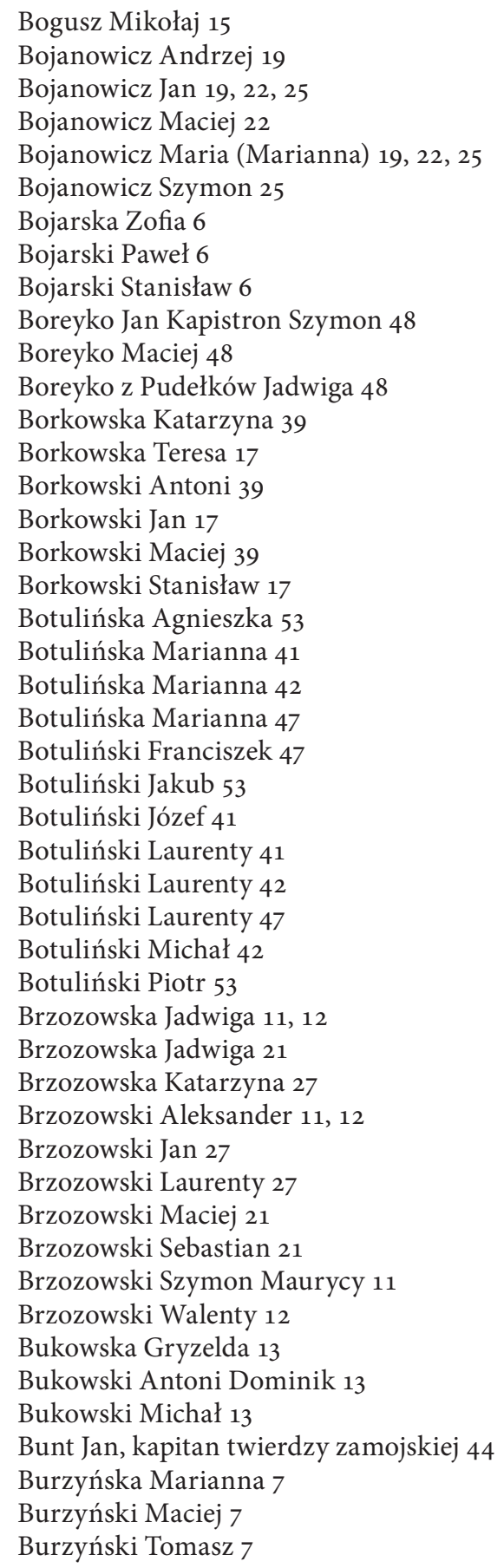

Bystrzejowski Michał 23

Bzowski Józef 46

Cętkowska (Częntkowska) Agnieszka 80

Cętkowska Katarzyna 80

Cętkowski (Częntkowski) Franciszek 77

Cętkowski Jan 80

Chamiec zob. Lipska z Chamców

Chmielecka Anna 56, 58, 61

Chmielecka Anna 76

Chmielecka Katarzyna 63

Chmielecka z Łaszczów Urszula 76

Chmielecki Albert 61

Chmielecki Grzegorz 58

Chmielecki Jakub 56, 58, 61

Chmielecki Jakub 63

Chmielecki Maciej 56

Chmielecki Marcjan 76

Chmielecki Szymon 63

Chociwska Anna 84

Chociwski Adalbert 84

Chociwski Ignacy Michał 84

Chodziejowska zob. Domaszewska z Chodziejowskich

Chojecka Teofila 57, 59, 62

Chojecki Franciszek 62

Chojecki Kazimierz 59

Chojecki Stanisław, ojciec 57, 59, 62

Chojecki Stanisław, syn 57

Chomicka Marianna 98

Chomicka Zofia 100

Chomicki Franciszek 100

Chomicki Michał, ojciec 98

Chomicki Michał, syn 98, 100

Chorbaszewska Anna 94

Chorbaszewski Adalbert 94

Chorbaszewski Antoni Jan 94

Chruszczewska Faustyna 406

Chudzicka Katarzyna 85, 86, 88, 89, 92

Chudzicka Marianna 97, 99

Chudzicki Adalbert 86

Chudzicki Antoni 85

Chudzicki Benedykt Józef 89

Chudzicki Jakub 88

Chudzicki Jakub 97, 99

Chudzicki Jan 85, 86, 88, 89, 92

Chudzicki Jan Antoni 97 
Chudzicki Mateusz 92

Chudzicki Paweł 99

Ciążyńska z Bystrzykowskich Maria

Egipcjana 93, 95, 96

Ciążyński Andrzej 96

Ciążyński Antoni 93

Ciążyński Feliks Antoni Jan 95

Ciążyński Jan Antoni Michał 93, 95, 96

Cichoń zob. Żołyńska z Cichoniów

Cichowska Katarzyna 74

Cichowska Regina 81, 82, 83

Cichowski Albert 81, 82, 83

Cichowski Błażej 81

Cichowski Kazimierz 74

Cichowski Maciej 83

Cichowski Sebastian 74

Cichowski Tomasz 82

Cykowska Regina 78

Cykowski Andrzej 78

Cykowski Jerzy 90

Cykowski Teodor 78

Czajkowska Marianna 23

Czarniecka Honorata 101

Czarniecka z Lipskich Anna 101

Czarniecki Jan 101

Czarniowska Zofia 70

Czarniowski Albert, ojciec 70

Czarniowski Albert, syn 70

Czarnołuska Anna 71

Czarnołuska Maryna 68

Czarnołuska zob. Heydyman z Czarnołuskich

Czarnołuski Andrzej 68

Czarnołuski Laurenty 71

Czarnołuski Sebastian 68

Czarnołuski Sebastian 71

Czechowska Anna 73

Czechowski Jakub 73

Czechowski Stanisław 73

Czernecka Zofia 72

Czernecki Jakub 72

Czernecki Marcin 72

Czerniawska Ewa 79

Czerniawski Albert 79

Czerniawski Józef 79

Czerniecka Anna 69

Czerniecki Laurenty 69
Czerniecki Marcin 69

Czerwińska Regina 64, 65, 66

Czerwińska Zuzanna 67

Czerwiński Albert 67

Czerwiński Jan 64, 65, 66

Czerwiński Kazimierz 64

Czerwiński Krzysztof 66

Czerwiński Michał 65

Czerwiński Paweł 67

Czeska zob. Lipska z Czeskich

Czeski Antoni 276

Czuryło Jan, ojciec 75

Czuryło Jan, syn 75

Czuryło Katarzyna 75

Czuryło zob. Komadowska z Czuryłów

Czyżowska Joanna 87

Czyżowski Jan 87, 91

Czyżowski Sebastian 87

Dąbkowska Marianna 144

Dąbkowski Dominik 144

Dąbkowski Laurenty 144

Dąbrowska Anna 107

Dąbrowska Katarzyna 114

Dąbrowska Katarzyna 141

Dąbrowska Marianna 117

Dąbrowski Albin Kazimierz 141

Dąbrowski Jan 114

Dąbrowski Jan 117

Dąbrowski Kazimierz 117

Dąbrowski Marcin 107

Dąbrowski Marcin 114

Dąbrowski Mikołaj 107

Dąbrowski Tadeusz 141

Dobrucka Agnieszka 109, 111, 112

Dobrucka Agnieszka 124, 127, 129

Dobrucka Anna 104

Dobrucka Barbara 102, 103

Dobrucka Jadwiga 134, 135, 142, 143

Dobrucka Katarzyna 120

Dobrucka Katarzyna 130, 131, 132, 136, 138

Dobrucka Teresa 145

Dobrucka z Dworników Regina 122

Dobrucka z Szumilaków Marianna 149

Dobrucka z Wolańczyków Marianna 146,148

Dobrucki Adalbert 138 
Dobrucki Adalbert 142

Dobrucki Adalbert 145

Dobrucki Albert 102

Dobrucki Albert 104

Dobrucki Albert 109, 111, 112

Dobrucki Albert 125

Dobrucki Antoni Feliks 148

Dobrucki Bartłomiej 111

Dobrucki Bartłomiej 130, 131, 132, 136, 138

Dobrucki Bartłomiej, ojciec 122, 125, 126

Dobrucki Bartłomiej, syn 122

Dobrucki Jakub 120

Dobrucki Jan 126

Dobrucki Jan Kanty 136

Dobrucki Józef 127

Dobrucki Józef 127

Dobrucki Krzysztof 104

Dobrucki Krzysztof 143

Dobrucki Łukasz 129

Dobrucki Maciej 124

Dobrucki Maciej 135

Dobrucki Maciej 149

Dobrucki Marcin 102, 103

Dobrucki Marcin 112

Dobrucki Marcin 124, 127, 129

Dobrucki Marcin 146

Dobrucki Michał 130

Dobrucki Michał 131

Dobrucki Michał 134, 135, 142, 143

Dobrucki Mikołaj 120

Dobrucki Piotr Paweł 149

Dobrucki Sebastian 109

Dobrucki Sebastian 134

Dobrucki Stanisław 103

Dobrucki Szymon, podstoli żytomierski 145

Dobrucki Tomasz 132

Dobrucki Tomasz 146, 148

Dobrzycka Helena 119

Dobrzycki Andrzej 119

Dobrzycki Kazimierz, wojskowy 119

Domaszewska Katarzyna 133, 140

Domaszewska z Chodziejowskich Elżbieta 147

Domaszewski Dominik 133

Domaszewski Jan Melchior Gaspar 147

Domaszewski Maciej 140

Domaszewski Sebastian 133, 140
Dombrowska Anastazja 137

Dombrowski Ignacy 137

Dombrowski Józef 137

Dramińska zob. Kozłowska z Dramińskich

Drozd zob. Bielecka Klara

Drużbic Jan Stanisław, łowczy horodelski 461

Drużbic Teofila Konstancja 461

Drużbic zob. Silnicka z Drużbiców

Drygalski Jan 139

Dubrawski Adalbert 118

Duchnicka Jadwiga 105, 106

Duchnicka Jadwiga 121, 123

Duchnicka Zofia 113

Duchnicki Andrzej 113

Duchnicki Andrzej 121

Duchnicki Jan 105, 106

Duchnicki Jan 113

Duchnicki Kazimierz 106

Duchnicki Łukasz 121, 123

Duchnicki Marcin 105

Duchnicki Piotr 123

Dwornik zob. Dobrucka

Dworzańska Marianna 116

Dworzańska Zofia 128

Dworzański Antoni 128

Dworzański Michał 128

Dworzański Mikołaj 116

Dworzański Sebastian 116

Dydyńska Barbara 110

Dydyński Antoni 110

Dydyński Antoni Krzysztof 110

Dziewałtowski Gintoft Antoni Kazimierz 115

Dziewałtowski Gintoft Jan, starosta terleszyński 115

Dzikowska Anna 108

Dzikowski Jan 108

Dzikowski Walenty 108

Frankowska Elżbieta 150

Frankowski Józef 150

Frankowski Stanisław 150

Gaładzińska Agnieszka 152

Gaładziński Albert 152

Gaładziński Kazimierz 152 
Gałęzowska ze Szczepanowskich Anna 158

Gałęzowski Grzegorz 158

Gałęzowski Mikołaj 158

Gardysawska Rozalia 171

Gardysawski Adalbert 171

Gardysawski Sebastian 171

Gębalska Apolonia 169

Gębalski Grzymała Grzegorz Jakub 169

Gębalski Grzymała Józef 169

Gębarzewska Jadwiga 168

Gębarzewski Jan, ojciec, łowczy nurski 168

Gębarzewski Jan, syn 168

Głębocki Mikołaj 110

Głuszkowska zob. Pajewska z Głuszkowskich

Gołębiowski Jan Maciej 164

Gołębiowska Agnieszka 164, 166

Gołębiowska Marianna 165

Gołębiowska Rozalia 167

Gołębiowska ze Skibickich Anna 173

Gołębiowski Adalbert 166

Gołębiowski Andrzej 173

Gołębiowski Antoni 165

Gołębiowski Laurenty 173

Gołębiowski Michał 165

Gołębiowski Michał, ojciec 167

Gołębiowski Michał, syn 167

Gołębiowski Stanisław 164, 166

Goniprowska zob. Winiarska z Goniprowskich

Górecki Michał 163

Górska Anna 153

Górski Andrzej, ojciec 153

Górski Andrzej, syn 153

Grabińska Katarzyna 162

Grabińska Leonora Anna 159

Grabińska Marianna 160

Grabińska Teresa 159

Grabiński Szymon 159, 160, 162

Grabiński Szymon, syn 162

Grabowska Agnieszka 157

Grabowska Marianna 161

Grabowski Fabian Sebastian 161

Grabowski Stanisław 157

Grabowski Stefan 161

Grabowski Walenty 157
Gruszecka z Kuśmirczaków Agnieszka 170,172

Gruszecka Zofia 156

Gruszecki Jakub 156

Gruszecki Jan 170, 172

Gruszecki Marcin 172

Gruszecki Szymon 156

Gruszecki Tomasz 170

Grzębska Krystyna 154

Grzębski Piotr 154

Grzębski Szymon 154

Grzymała Albert 155

Grzymała Konstancja 155

Grzymała Zuzanna Maria 155

Guszkowska Anna 151

Guszkowski Albert 151

Guszkowski Wincenty 151

Heydyman Melchior 175

Heydyman z Czarnołuskich Teofila 175

Hubowska Katarzyna 174

Hubowski Albert 174

Hubowski Jan 174

Humińska Anna 176

Humiński Gabriel 176

Humiński Leopold 176

Jabłońska Regn 178

Jabłońska Zuzanna 177

Jabłoński Jakub 177

Jabłoński Jan 178

Jabłoński Marcin 178

Jabłoński Sebastian 177

Jagiełłowicz (Orłowska) Konstancja 395

Jakubowski Stanisław 181

Janczyńska Anna 180

Janczyński Antoni 180

Janczyński Stanisław 180

Janicka Marianna 184

Janicki Jakub 184

Janicki Michał 184

Jankowska z Ochockich Ewa 182

Jankowski Jan 182

Jankowski Marcin 182

Januszowska z Komadowskich

Agnieszka 185

Januszowski Jan 185 
Januszowski Tomasz 185

Jaworska Dorota 183

Jaworski Antoni 183

Jaworski Stanisław 183

Jędrzejowska Katarzyna 179

Jędrzejowski Michał 179

Kamińska Anna 258

Kamińska z Trojanowskich Katarzyna 216

Kamiński Feliks 258

Kamiński Franciszek 216

Kamiński Maciej 258

Kamiński Teofil 216

Karmazyn zob. Koszczakiewicz z Karmazynów

Kasicka Łucja 200

Kasicka z Bogackich Katarzyna 204, 206

Kasicka z Szumilaków Marianna 233

Kasicki Antoni 204

Kasicki Franciszek 200

Kasicki Michał 206

Kasicki Michał, wójt 233

Kasicki Stanisław 200

Kasicki Stanisław, rajca narolski 204; burmistrz 206

Kasicki Szymon Tadeusz 233

Kasper zob. Kwiatkowska z Kasprów

Kasperska z Kaweckich Apolonia 225, 235

Kasperska zob. Śmietanowicz z Kasperskich

Kasperski Maciej 225, 235

Kasperski Michał 225

Kawecka zob. Kasperska z Kaweckich

Kawecka Zofia 232

Kawecki Maciej 232

Kawecki Marcin 232

Kędzierska Ewa 190

Kędzierski Andrzej 190

Kędzierski Jan 190

Kęsicka Magdalena 188

Kęsicka Urszula 286

Kęsicki Damian Jan 188

Kęsicki Kazimierz 188

Kęsicki Paweł Stanisław, cześnik nowogrodzki 284, 286

Kierzniowski Michał Aleksander Feliks Walery 247

Kierzśniowska Konstancja Tekla 243
Kierzśniowska z Węgleńskich Ludwika

243,247

Kierzśniowski Michał, cześnik latyczowski 243,247

Kliński Tomasz, rotmistrz 284

Klisiewicz Agnieszka 236, 237

Klisiewicz Andrzej 237

Klisiewicz Jakub 236, 237

Kłoczkowska Jadwiga 191

Kłoczkowska Zofia 193, 194

Kłoczkowski Błażej 193

Kłoczkowski Jan 191

Kłoczkowski Jan 193, 194

Kłoczkowski Józef 194

Kłoczkowski Tomasz 191

Kolbuszewska Agnieszka 203

Kolbuszewska z Krajewskich Katarzyna 218

Kolbuszewska z Piwuckich Katarzyna 240, 249

Kolbuszewska zob. Ostrowska z Kolbuszewskich

Kolbuszewski Jan 203

Kolbuszewski Kazimierz 240

Kolbuszewski Laurenty 218

Kolbuszewski Laurenty 240, 249

Kolbuszewski Marcin 203

Kolbuszewski Marcin 218

Kolbuszewski Piotr 249

Komadowska Marianna 250, 251, 252, 255, 259

Komadowska Marianna 256

Komadowska z Czuryłów Zofia 253

Komadowska zob. Januszowska z Komadowskich

Komadowski Antoni 256

Komadowski Antoni 259

Komadowski Jan 250

Komadowski Jan 253

Komadowski Kazimierz 253

Komadowski Kazimierz 256

Komadowski Laurenty 252

Komadowski Marcin 251

Komadowski Sebastian 255

Komadowski Tomasz 250, 251, 252, 255, 259

Komnacka z Szularzów Marianna 205

Komnacki Kazimierz 205

Komnacki Paweł 205 
Konopka Mateusz 199

Konopka Tomasz 199

Konopka Zofia 199

Korabiowska Marianna 219, 220, 221[?]

Korabiowski Antoni 221

Korabiowski Józef 219, 220, 221

Korabiowski Konstanty 220

Korabiowski Marcin 219

Korecka Regina 186

Korecki Sebastian 186

Korecki Stanisław 186

Kossak zob. Malinowska z Kossaków

Koszczakiewicz Maciej 257

Koszczakiewicz Tomasz 257

Koszczakiewicz z Karmazynów

Krystyna 257

Koszucka Agnieszka 196, 202

Koszucki Albert 202

Koszucki Grzegorz 196, 202

Koszucki Jakub 196

Kozłowska Agnieszka 197

Kozłowska Jadwiga 208

Kozłowska Katarzyna 198, 201

Kozłowska Łucja 192

Kozłowska Regina 189

Kozłowska Teresa 245

Kozłowska z Dramińskich Elżbieta 254

Kozłowska zob. Krzyszkiewicz z Kozłowskich

Kozłowska Zofia 187

Kozłowski Adalbert 245

Kozłowski Albert 187

Kozłowski Albert 189

Kozłowski Antoni 197

Kozłowski Antoni 201

Kozłowski Antoni 245

Kozłowski Ignacy 254

Kozłowski Jakub 198

Kozłowski Jan 192

Kozłowski Kazimierz Grzegorz 254

Kozłowski Krzysztof 208

Kozłowski Laurenty 189

Kozłowski Paweł 208

Kozłowski Sebastian 192

Kozłowski Sebastian 198, 201

Kozłowski Stanisław 187

Kozłowski Stanisław 197
Krajewska Regina 195

Krajewska zob. Kolbuszewska z Krajewskich

Krajewski Kazimierz 195

Krajewski Piotr 195

Krasowska zob. Szulc z Krasowskich

Krauzewska (Bunt) Teresa 44

Krupska Anna 207

Krupski Andrzej 207

Krupski Grzegorz 207

Krzeczkowska Justyna 229

Krzeczkowski Antoni 229

Krzeczkowski Błażej Antoni 229

Krzemieńska Zofia 213

Krzemieński Antoni 213

Krzemieński Jan 213

Krzynicka zob. Axan

Krzyszkiewicz Albert 214, 217

Krzyszkiewicz Antoni 238

Krzyszkiewicz Jadwiga 227

Krzyszkiewicz Jakub 214

Krzyszkiewicz Józef 242

Krzyszkiewicz Katarzyna 230, 231, 238, 242

Krzyszkiewicz Sebastian 217

Krzyszkiewicz Sebastian 227

Krzyszkiewicz Sebastian, ojciec 230, 231, 238,242

Krzyszkiewicz Sebastian, syn 230

Krzyszkiewicz Tomasz 227

Krzyszkiewicz Tomasz 231

Krzyszkiewicz z Kozłowskich Marianna 214, 217

Krzywiecka z Mogilnickich Zuzanna 222, 223, 224, 226, 228, 234

Krzywiecki Adam 224

Krzywiecki Franciszek 228

Krzywiecki Ignacy 223

Krzywiecki Józef 222

Krzywiecki Michał 222, 223, 224, 226, 228, 234

Krzywiecki Tomasz 226

Kulikowska Anna 115

Kulikowska Wiktoria 210, 211, 212

Kulikowski Andrzej 115

Kulikowski Józef Antoni 210

Kulikowski Józef Antoni 212

Kulikowski Kazimierz 210, 211, 212

Kulikowski Laurenty Kajetan 211 
Kułakowska Katarzyna 241, 244

Kułakowski Jakub 244

Kułakowski Szymon 241, 244

Kułakowski Tomasz 241

Kurowska Marianna Tekla 246

Kurowska z Rościszewskich Rozalia 246, 248

Kurowski Leopold 248

Kurowski Piotr Ignacy 246, 248

Kuśmirczak zob. Gruszecka z Kuśmirczaków

Kwiatkowska z Kasprów Katarzyna 209, 215

Kwiatkowski Balcer 215

Kwiatkowski Franciszek Ksawery 209

Kwiatkowski Jakub 209, 215

Kwiecińska Anna 239

Kwieciński Józef 239

Kwieciński Kazimierz 239

Laskowska zob. Klisiewicz z Laskowskich

Lesiecka Anna 461

Leszczyńska Jadwiga 275, 277

Leszczyński Franciszek 275, 277

Leszczyński Laurenty 277

Leszczyński Tomasz 275

Lewicka Regina 264, 265, 266, 268, 269

Lewicki Antoni 268

Lewicki Hiacynt 265

Lewicki Jan 264, 265, 266, 268, 269

Lewicki Józef 264

Lewicki Laurenty 266

Lewicki Michał 269

Lipska Agnieszka 263

Lipska Cecylia Elżbieta 272

Lipska Justyna Prakseda 273

Lipska Klara 273

Lipska Rozalia Kandyda 270

Lipska z Chamców Marianna 261, 262

Lipska z Czeskich Zofia 274, 276

Lipska z Łętkowskich Anna 267, 270, 272

Lipska zob. Czarniecka z Lipskich

Lipska Zofia 262

Lipski Andrzej 261, 262

Lipski Andrzej 286

Lipski Antoni 261

Lipski Antoni 274, 276

Lipski Benedykt 267

Lipski Józef, skarbnik bełski 267, 270, 272
Lipski Kazimierz Józef 263

Lipski Konstanty Grzegorz 276

Lipski Marcin 274

Lipski Samuel 273

Lipski Zbożny 263

Lisowska (Cykowska) Marianna 90

Lisowska Marianna 278

Lisowska Marianna 279, 280

Lisowski Adalbert 278

Lisowski Adalbert 280

Lisowski Adam 278

Lisowski Józef, ojciec 279, 280

Lisowski Józef, syn 279

Litwińska Jadwiga 260

Litwiński Albert 260

Litwiński Jakub 260

Lubawska z Ponińskich Elżbieta 281

Lubawski Marcin 281

Lubawski Wincenty 281

Lubrzańska z Przygodzińskich

Marianna 271

Lubrzański Franciszek 271

Lubrzański Urban 271

Łagowska Marianna 292, 293

Łagowska Regina 283

Łagowski Józef 292

Łagowski Mikołaj 283

Łagowski Sebastian 293

Łagowski Stanisław 283

Łagowski Stanisław 292, 293

Łaszcz Aleksander, starosta grabowiecki 461

Łaszcz Jan Stefan 286

Łaszcz Jerzy 284

Łaszcz Katarzyna 282

Łaszcz Kazimierz 282, 284, 285, 286

Łaszcz Michał 285

Łaszcz z Wojutyńskich Konstancja 282, 284, 285,286

Łaszcz zob. Chmielecka z Łaszczów

Łątkowska zob. Lipska z Łętkowskich

Łepkowska zob. Nowacka z Łepkowskich

Łotecka Marianna 287, 288

Łotecki Hieronim 287, 288

Łotecki Jan Andrzej 288

Łotecki Stanisław Antoni 287

Łowiecka Agnieszka 290 
Łowiecki Laurenty 290

Łowiecki Sebastian 290

Łoyko zob. Niegardowska z Łoyków

Łoyko zob. Plucińska z Łoyków

Łubkowska Barbara 289

Łubkowski Kazimierz Marcin 289

Łubkowski Michał 289

Łukowska Anna 294

Łukowska Ewa 291

Łukowski Adam 291

Łukowski Albert 291

Łukowski Hieronim 294

Łukowski Mathias 294

Łysakowska Jadwiga 295, 296, 297

Łysakowski Jakub 296

Łysakowski Krzysztof 297

Łysakowski Łukasz 295, 296, 297

Łysakowski Marcin 295

Magnuska Marianna 310

Magnuski Mikołaj 310

Magnuski Szymon 310

Majewska Katarzyna 338, 339

Majewska Zofia 337

Majewski Adalbert 337

Majewski Franciszek Antoni 339

Majewski Michał 338

Majewski Stanisław 337

Majewski Stanisław, malarz 338, 339

Makowska Katarzyna 318, 320, 322, 323

Makowska Katarzyna 331, 332, 333, 334

Makowska Łucja 341

Makowska Tańka 299

Makowska Teresa 298

Makowski Aleksy Jakub 333

Makowski Andrzej 298, 299

Makowski Antoni 318

Makowski Antoni 320

Makowski Grzegorz 298

Makowski Jan 341

Makowski Joachim Krzysztof 331

Makowski Krzysztof 331, 332, 333, 334

Makowski Maciej 332

Makowski Michał 299

Makowski Paweł 318, 320, 322, 323

Makowski Paweł 330

Makowski Piotr Paweł 334
Makowski Stanisław 341

Makowski Tomasz 322

Malicka Katarzyna 335

Malicki Jakub 335

Malicki Szymon 335

Malinowska Anna 302

Malinowska z Kossaków Anastazja 343, 344

Malinowski Błażej 344

Malinowski Jan 343, 344

Malinowski Michał 302

Malinowski Sebastian 343

Malinowski Stanisław 302

Małaszewska Anna 327

Małaszewski Jan 327

Małaszewski Tomasz 327

Małdrzyk zob. Olszańska z Małdrzyków

Mandecka (Rykowska) Apolonia 438

Maniewska Zofia 336

Maniewski Adalbert 336

Maniewski Stanisław 336

Mazurek Marianna 118

Michalska Anna 301

Michalska Zofia 308

Michalski Antoni 301

Michalski Józef 308

Michalski Szymon 301

Michalski Tomasz 308

Michałowska Zofia 303, 306

Michałowski Michał 303, 306

Michałowski Sebastian 306

Michałowski Szymon 303

Mogilnicka (Czyżowska) Joanna 91

Mogilnicka Elżbieta 46

Mogilnicka Joanna 317

Mogilnicka Katarzyna 311, 313, 314, 316

Mogilnicka Katarzyna 324

Mogilnicka Marianna 305, 307

Mogilnicka Marianna 324, 326

Mogilnicka Rozalia 305

Mogilnicka z Tymińskich Konstancja 315, $319,321,325,329$

Mogilnicka zob. Krzywiecka z Mogilnickich

Mogilnicki Aleksander Błażej 315

Mogilnicki Aleksander, łowczy żytomierski 305, 307

Mogilnicki Antoni Bazyli 314

Mogilnicki Franciszek Ksawery 307 
Mogilnicki Franciszek, podwojewodzi stężycki 311, 313, 314, 316, 327

Mogilnicki Ignacy 324, 326

Mogilnicki Ignacy Łukasz 311

Mogilnicki Jakub 321

Mogilnicki Jan 315, 319, 321, 325, 329

Mogilnicki Jan Aleksander 313, 327

Mogilnicki Jan Aleksander 328

Mogilnicki Klemens Ignacy 325

Mogilnicki Łukasz Antoni Józef 326

Mogilnicki Paweł 317

Mogilnicki Stanisław Józef 316

Mogilnicki Tomasz 319

Mosiewicz Brygida 300

Mosiewicz Marcin 300

Mosiewicz Marianna 300

Mozgawska Teofila 284

Mroczkowska Zofia 304, 309, 312

Mroczkowski Józef 312

Mroczkowski Maciej 304

Mroczkowski Sebastian 304, 309, 312

Mroczkowski Stanisław 309

Mulacka Katarzyna 342

Mulacki Adalbert 342

Mulacki Marcin 342

Mulak (Makowska) Marianna 330

Mulak zob. Bielecka z Mulaków

Myszkowska Zofia 340

Myszkowski Jan 340

Myszkowski Kazimierz 340

Nartowska (Rogozińska) Katarzyna 437

Nartowska (Sobierajska) Teresa 471

Nartowska Anna 372

Nartowska Ewa 361, 366

Nartowska Gryzelda 349

Nartowska Ludwika 368

Nartowska z Bestkowskich Katarzyna 374, 375,378

Nartowska z Piątkowskich Regina 356, 359, $360,362,364,365$

Nartowska zob. Radecka z Nartowskich

Nartowska zob. Suchodolska z Nartowskich

Nartowski Adalbert Jakub 375

Nartowski Albert 364

Nartowski Andrzej 361

Nartowski Antoni 360
Nartowski Franciszek 361, 366

Nartowski Gaspar Józef 372

Nartowski Ignacy Kazimierz 349

Nartowski Jan 349

Nartowski Jan 362

Nartowski Jan Antoni 368

Nartowski Józef 368

Nartowski Józef 374, 375, 378

Nartowski Justyn Aleksander 356

Nartowski Kazimierz 365

Nartowski Krzysztof 359

Nartowski Ludwik 374

Nartowski Łukasz 366

Nartowski Mikołaj 372

Nartowski Stanisław 356, 359, 360, 362, 364,365

Nawrocka Anna 351, 352

Nawrocki Jan Duklan 352

Nawrocki Kazimierz, ojciec 351, 352

Nawrocki Kazimierz, syn 351

Nawrotowska Jadwiga 345, 347

Nawrotowski Andrzej 345

Nawrotowski Jakub 345, 347

Nawrotowski Szymon 347

Niegardowska Agnieszka 358

Niegardowska Agnieszka 379

Niegardowska Dorota 370, 371

Niegardowska Helena 354

Niegardowska Jadwiga 376, 377

Niegardowska Katarzyna 348, 350

Niegardowska Marianna 367, 369

Niegardowska Marianna 373

Niegardowska Marianna 380, 381, 382, 384

Niegardowska z Łoyków Agnieszka 353, 355,357

Niegardowska Zofia 383

Niegardowski Adalbert 367

Niegardowski Adalbert 373

Niegardowski Adalbert 376, 377

Niegardowski Albert 353

Niegardowski Albert 358

Niegardowski Andrzej 383

Niegardowski Antoni 367, 369

Niegardowski Błażej 355

Niegardowski Dominik 363

Niegardowski Franciszek 350

Niegardowski Grzegorz Józef 382 
Niegardowski Hiacynt 354

Niegardowski Hiacynt 358

Niegardowski Jakub 348

Niegardowski Jakub Krzysztof 384

Niegardowski Jan 348, 350

Niegardowski Jan Andrzej 380

Niegardowski Joachim Mikołaj 379

Niegardowski Kazimierz 357

Niegardowski Laurenty 381

Niegardowski Marcin 370

Niegardowski Mikołaj 380, 381, 382, 384

Niegardowski Sebastian 354

Niegardowski Sebastian 370, 371

Niegardowski Sebastian 373

Niegardowski Sebastian 376

Niegardowski Stanisław 353, 355, 357, 363

Niegardowski Stanisław 383

Niegardowski Sylwester Sebastian 377

Niegardowski Tomasz 371

Niegardowski Tomasz 379

Niegardowski Walenty 369

Niemirska Elżbieta 346

Niemirski Albert 346

Niemirski Jan 346

Nowacka z Łepkowskich Zofia 385

Nowacki Feliks Hilary 385

Nowacki Stefan, nauczyciel 385

Ogromska Anna 409

Ogromski Jakub 409

Ogromski Laurenty 409

Okorski Franciszek, administrator 406

Olewińska Marianna 405

Olewiński Michał 405

Olewiński Tadeusz Marcin 405

Olszańska z Małdrzyków Jadwiga 400

Olszański Stanisław 400

Olszański Szymon 400

Olszowska Zuzanna 386

Olszowski Albert 386

Olszowski Andrzej 386

Orlikowska Katarzyna 398, 399

Orlikowski Bazyli 398, 399

Orlikowski Laurenty 399

Orlikowski Tomasz 398

Orłowska Konstancja 402

Orłowska Marianna 404
Orłowski Antoni 395

Orłowski Antoni 402

Orłowski Błażej 404

Orłowski Józef Franciszek 402

Orłowski Teodor 404

Osadzińska zob. Rużycka

Osmólska Barbara 389, 390

Osmólska Maryna 387

Osmólski Albert 387

Osmólski Albert 390

Osmólski Albert, ojciec 389, 390

Osmólski Albert, syn 389

Osmólski Szymon 387

Ostrowska Agnieszka 401, 403

Ostrowska Anna 397

Ostrowska Katarzyna 388

Ostrowska Marianna 391, 392, 393

Ostrowska Regina 407, 408

Ostrowski Adam Albert 411

Ostrowski Albert 388

Ostrowski Albert 396

Ostrowski Albert 397

Ostrowski Franciszek 401, 403

Ostrowski Franciszek 413

Ostrowski Jakub 392

Ostrowski Jakub 403

Ostrowski Jakub 407, 408

Ostrowski Jan Baptysta 410

Ostrowski Józef 412

Ostrowski Maciej 393

Ostrowski Maciej 407

Ostrowski Maciej 410, 411, 412, 413

Ostrowski Marcin 388

Ostrowski Marcin, ojciec 391, 392, 393

Ostrowski Marcin, syn 391

Ostrowski Michał 394

Ostrowski Mikołaj 397

Ostrowski Sebastian 408

Ostrowski Walenty 401

Ostrowski z Kolbuszewskich Marianna 410, $411,412,413$

Pajewska z Głuszkowskich Marianna 417

Pajewski Józef Aleksander 417

Pajewski Mikołaj 417

Piątkowska Agnieszka 418

Piątkowska zob. Nartowska z Piątkowskich 
Piątkowski Grzegorz 418

Piątkowski Józef 418

Piwucka zob. Kolbuszewska z Piwuckich

Plucińska Apolonia 421

Plucińska z Łoyków Katarzyna 423, 424

Pluciński Antoni 421

Pluciński Franciszek 423

Pluciński Marcin 424

Pluciński Mikołaj 423, 424

Pluciński Tomasz 421

Podgórski Jakub 420

Pogorzelska Dorota 416

Pogorzelska Regina 414

Pogorzelska Regina 415

Pogorzelski Jakub 415

Pogorzelski Maciej 414

Pogorzelski Maciej 415

Pogorzelski Paweł 416

Pogorzelski Sebastian, burmistrz 414

Pogorzelski Szymon 416

Ponińska zob. Lubawska z Ponińskich

Potocka Katarzyna 422

Potocki Józef 422

Potocki Stanisław, ekonom, burgrabia 422

Przestrzelska Marianna 419

Przestrzelska Zofia 419

Przestrzelski Ignacy 419

Przygodzińska zob. Lubrzańska

z Przygodzińskich

Pudełko zob. Boreyko z Pudełków

Rachańska Regina 425, 426

Rachański Jan, ojciec 425, 426

Rachański Jan, syn 426

Rachański Tomasz 425

Radecka Marianna 431

Radecka z Nartowskich Marianna 434, 439

Radecki Feliks 431

Radecki Franciszek 434, 439

Radecki Paweł Ignacy 431

Radecki Sebastian Antoni 434

Ranizeska Agnieszka 443

Ranizeski Łukasz 443

Ranizeski Marcin 443

Rayska Agnieszka 432

Rayska Anna 435
Rayska Katarzyna 432

Rayski Adalbert 435

Rayski Sebastian 432

Rayski Tomasz 435

Rogowska Zofia 429

Rogowski Albert 429

Rogowski Paweł 429

Rogoziński Paweł 437

Romańska Krystyna 441

Romański Jakub, ojciec 441

Romański Jakub, syn 441

Rościszewska zob. Kurowska z Rościszewskich

Rozańska Agnieszka 442

Rozańska Helena 427, 428

Rozański Błażej 428

Rozański Jakub, ojciec 442

Rozański Jakub, syn 442

Rozański Jan 427

Rozański Walenty 427, 428

Rozwadowska Marianna 430

Rozwadowski Bartłomiej 430

Rozwadowski Szymon 430

Rużycka Ewa 440

Rużycka Katarzyna 436

Rużycka z Osadzińskich Salomea 444

Rużycki Andrzej 436

Rużycki Andrzej 440

Rużycki Jan 444

Rużycki Kazimierz 440

Rużycki Marcin 444

Rużycki Tomasz 436

Rykowska Apolonia 433

Rykowski Andrzej 433

Rykowski Antoni 433

Rykowski Antoni 438

Sawicka Krystyna 468

Sawicki Michał 468

Sawicki Szymon 468

Sawińska Helena 460

Sawiński Albert 460

Sawiński Walenty 460

Sędecka Marianna 496

Sędecki Stanisław 496

Sędecki Tomasz 496 
Silnicka (Dziewałtowska) Wiktoria 115

Silnicka Joanna Brygida 461

Silnicka Magdalena 115

Silnicka Wiktoria Bogumiła 466

Silnicka z Drużbiców Katarzyna Teresa 458, $459,461,464,466$

Silnicka Zofia 458

Silnicki Jan 115

Silnicki Jan Stefan, chorąży podolski, dziedzic 458, 459, 461, 464, 466

Silnicki Michał 464

Silnicki Róża Jan 459

Skalska Jadwiga 501, 504

Skalski Antoni 504

Skalski Laurenty 501, 504

Skalski Mateusz 501

Skibicka zob. Gołębiowska ze Skibickich

Skibińska Katarzyna 482

Skibińska Katarzyna 503

Skibińska Regina 498

Skibińska z Woydów Anna 502

Skibiński Adalbert 503

Skibiński Andrzej 482

Skibiński Gabriel 502

Skibiński Jakub 498

Skibiński Jakub 503

Skibiński Jan 502

Skibiński Józef 502

Skibiński Marcin 498

Skibiński Stefan 482

Skorodyńska Maryna 445

Skorodyński Andrzej 445

Skorodyński Maciej 445

Skotnicka Katarzyna 455, 456

Skotnicki Grzegorz 456

Skotnicki Jan 455

Skotnicki Kazimierz 456

Skotnicki Laurenty 455

Skowrońska Anna 494

Skowroński Antoni 494

Skowroński Kazimierz 494

Skulska Marianna 483, 484

Skulska Zofia 493

Skulski Antoni 493

Skulski Bartłomiej 483, 484

Skulski Ignacy Piotr 493
Skulski Laurenty 484

Skulski Mateusz 483

Słocińska Regina 472

Słociński Hiacynt 472

Słociński Laurenty 472

Sobierajska Marianna 470

Sobierajski Kazimierz 470

Sobierajski Samuel 471

Sobierajski Samuel Paweł 470

Sochanowska Agnieszka 448

Sochanowski Jakub 448

Sochanowski Stanisław 448

Sokalska Regina 420

Sokołowska Anna 446

Sokołowska Marianna (Maryna) 450, 457

Sokołowska Marianna 475

Sokołowski Andrzej 475

Sokołowski Jan 457

Sokołowski Jan 475

Sokołowski Krzysztof 446

Sokołowski Marcin 450

Sokołowski Paweł, szewc 450, 457

Sokołowski Stefan 446

Sokulska z Banasiów Zofia 474

Sokulski Dionizy 474

Sokulski Laurenty 474

Solska Barbara 449

Solska Barbara 469

Solski Albert 449

Solski Marcin 469

Solski Michał 449

Solski Mikołaj Franciszek 469

Sowińska Eufrozyna 467

Sowiński Jan 467

Sowiński Michał 467

Sroczkowski Andrzej, administrator 486

Stanisławska Zofia 451

Stanisławski Albert 451

Stanisławski Stanisław 451

Stankiewicz Katarzyna 499

Stankiewicz Laurenty 499

Stankiewicz Stanisław 499

Staszyńska Marianna 453

Staszyński Albert 453

Staszyński Walenty 453

Stawska Anna 465 
Stawska Joanna 465

Stawski Aleksander 465

Stocka Katarzyna 77

Styrpeko Anna 473

Styrpeko Ignacy 473

Styrpeko Stanisław 473

Suchodolska Barbara 481

Suchodolska z Nartowskich Rozalia 481, 487

Suchodolski Marcin 481, 487

Suska (Bielecka) Jadwiga 45

Syroczyńska Antonina 139

Szadowska Rozalia 490

Szadowski Jan 490

Szadowski Józef 490

Szajewska Agnieszka 492, 500

Szajewski Grzegorz Antoni 492

Szajewski Sebastian, ojciec 492, 500

Szajewski Sebastian, syn 500

Szarzyńska Katarzyna 476

Szarzyński Antoni 476

Szarzyński Jan 476

Szatkowska Katarzyna 452

Szatkowski Jan 452

Szatkowski Łukasz 452

Szczepanowska zob. Gałęzowska ze

Szczepanowskich

Szczepańska Agnieszka 463

Szczepański Andrzej 463

Szczepański Stefan 463

Szczeptowska Maryna 447

Szczeptowski Hieronim 447

Szczeptowski Maciej 447

Szczudłowska Ewa 488

Szczudłowski Jan 488

Szczudłowski Mikołaj 488

Szuchtan Rola Anna 480

Szuchtan Rola Jakub 480

Szuchtan Rola Marcin 480

Szularz zob. Komnacka z Szularzów

Szulc Marcin 478, 485

Szulc Michał Tomasz 478

Szulc z Krasowskich Anna 478, 485

Szumilak zob. Dobrucka z Szumilaków

Szumilak zob. Kasicka z Szumilaków

Szydłowska Zofia 497

Szydłowski Franciszek 497

Szydłowski Sebastian 497
Szymańska Katarzyna 477, 479

Szymański Bartłomiej 477

Szymański Krzysztof 477, 479

Szymański Marcin 479

Śliwińska Helena 462

Śliwiński Albert, ojciec 462

Śliwiński Albert, syn 462

Śmietanowicz Agnieszka Maryna 491

Śmietanowicz Ignacy Józef, komisarz 491

Śmietanowicz z Kasperskich Magdalena 491

Świątoniewska Katarzyna 495

Świątoniewska Zofia 489

Świątoniewski Bartłomiej 489

Świątoniewski Błażej 495

Świątoniewski Michał 495

Świątoniewski Stanisław 489

Świderska Katarzyna 454

Świderski Łukasz 454

Świderski Mikołaj 454

Tomaszewska Katarzyna 511

Tomaszewski Antoni 511

Tomaszewski Sebastian 511

Tomaszowska Marianna 507

Tomaszowski Andrzej 507

Tomaszowski Szymon 507

Topornicka Katarzyna 506

Topornicki Jan, ojciec 506

Topornicki Jan, syn 506

Toporowska Konstancja 509

Toporowski Antoni 509

Toporowski Stanisław 509

Trawińska Jadwiga 508

Trawiński Grzegorz 508

Trawiński Jan 508

Trojanowska zob. Kamińska z Trojanowskich

Trojańska Zofia 505

Trojański Błażej 505

Trojański Sebastian 505

Trząkowska Franciszka 513, 514, 515

Trząkowski Antoni Ksystus 513

Trząkowski Franciszek Michał 515

Trząkowski Józef, kamerdyner 513, 514, 515

Trząkowski Marcin Dominik 514

Trzeciecka Magdalena 510 
Trzeciecki Albert 510

Trzeciecki Kajetan Faustyn 510

Tymińska zob. Mogilnicka z Tymińskich

Tymowska Bogumiła 512

Tymowski Józef 512

Tymowski Piotr Paweł 512

Ujazdowska Salomea 516

Ujazdowska z Wyżgów Katarzyna 516

Ujazdowski Michał 516

Wąż Anna 518

Wąż Felicjan 518

Wicijowska Marianna 526

Wicijowska Teresa 527

Wicijowski Adam 526

Wicijowski Antoni 526

Wicijowski Błażej 527

Wicijowski Gaspar 527

Wiech (Ostrowska) Anna 396

Wigant Ertman 522

Wigant Konstancja 522

Wigant Ludwik 522

Wilczyńska Anna 520

Wilczyński Antoni 520

Wilczyński Walerian 520

Winiarska (Sroczkowska) Agnieszka 486

Winiarska z Goniprowskich Katarzyna 523, $524,525,528$

Winiarski Adalbert, administrator 523, 524, 525,528

Winiarski Fabian Sebastian 525

Winiarski Jakub 523

Winiarski Marcin 524

Wojszewska Brygida Teresa 519

Wojszewska Konstancja 519

Wojszewski Walenty 519

Wojutyńska zob. Łaszcz z Wojutyńskich

Wolańczyk zob. Dobrucka z Wolańczyków

Wolska Anastazja 521

Wolski Andrzej 521

Wolski Jakub 521

Wysocka Zofia 517

Wysocki Kazimierz 517

Wysocki Stanisław 517

Wyżga zob. Ujazdowska z Wyżgów
Zaleska Katarzyna 537

Zaleski Tomasz, ojciec 537

Zaleski Tomasz, syn 537

Załuska Jadwiga 532

Załuska Jadwiga 543

Załuski Albert 543

Załuski Andrzej 532

Załuski Łukasz 532

Załuski Michał 543

Zaremba Anna 531

Zaremba Franciszek 531

Zaremba Tomasz 531

Zawadzka Anna 546

Zawadzki Antoni 546

Zawadzki Jan 546

Zbiejowska Maryna 539

Zbiejowski Albert 539

Zbiejowski Jan 539

Ziebrowska Katarzyna 163

Zieleńska Agnieszka 538

Zieleńska Katarzyna 530

Zieleńska Marcjanna 529

Zieleńska Zofia 540

Zieleński Adam 530

Zieleński Albert 529

Zieleński Franciszek 530

Zieleński Jan 538

Zieleński Laurenty 540

Zieleński Paweł 538

Zieleński Stanisław 529

Zieleński Szymon 540

Zielińska Agnieszka 533

Zieliński Laurenty 533

Zieliński Marcin 533

Zubrzycka Regina 544

Zubrzycki Bartłomiej 544

Zubrzycki Jan 544

Żołyńska Anna 542

Żołyńska z Cichoniów Agnieszka 545

Żołyński Błażej 542

Żołyński Franciszek 545

Żołyński Maciej 542

Żołyński Stefan 545

Żukowska Zofia 534

Żukowski Gaspar 534

Żukowski Józef 534 
Żurakowska Anna 536

Żurakowski Gaspar 536

Żurakowski Marcin 536

Żurawska Agnieszka 535, 541
Żurawski Albert 541

Żurawski Grzegorz 535, 541

Żurawski Ignacy 535

\section{Chronologiczne zestawienie wypisów}

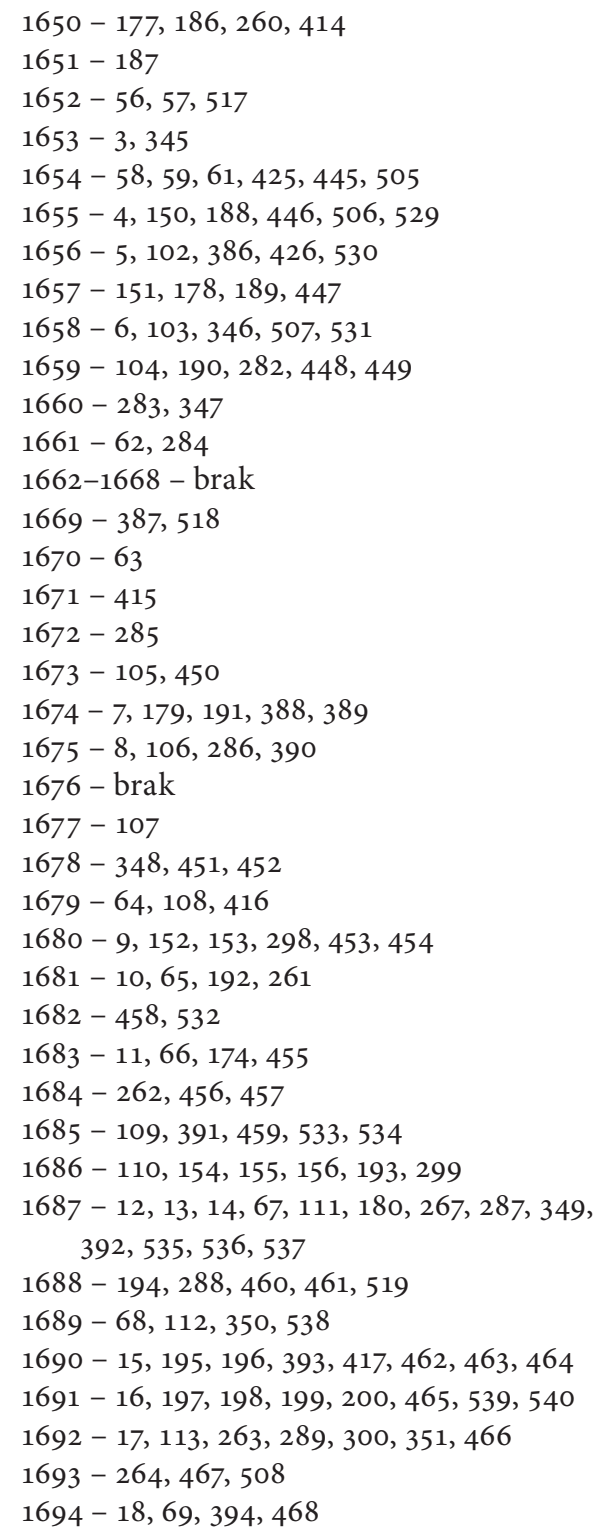

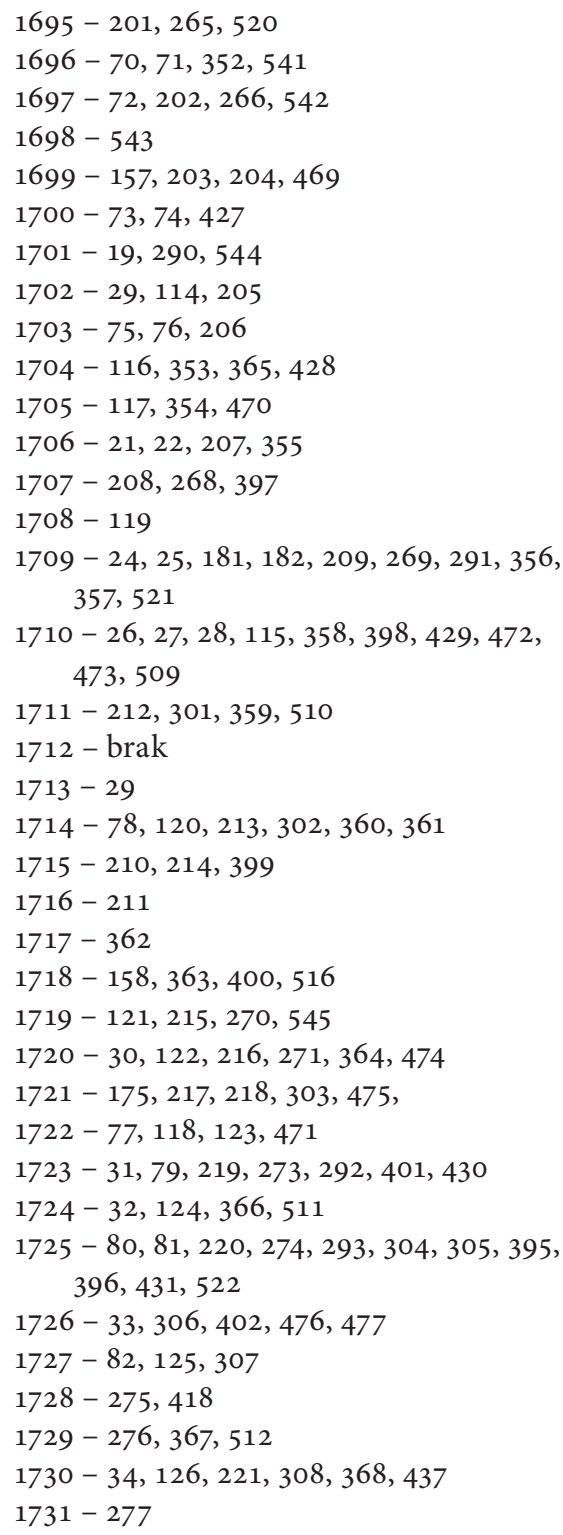




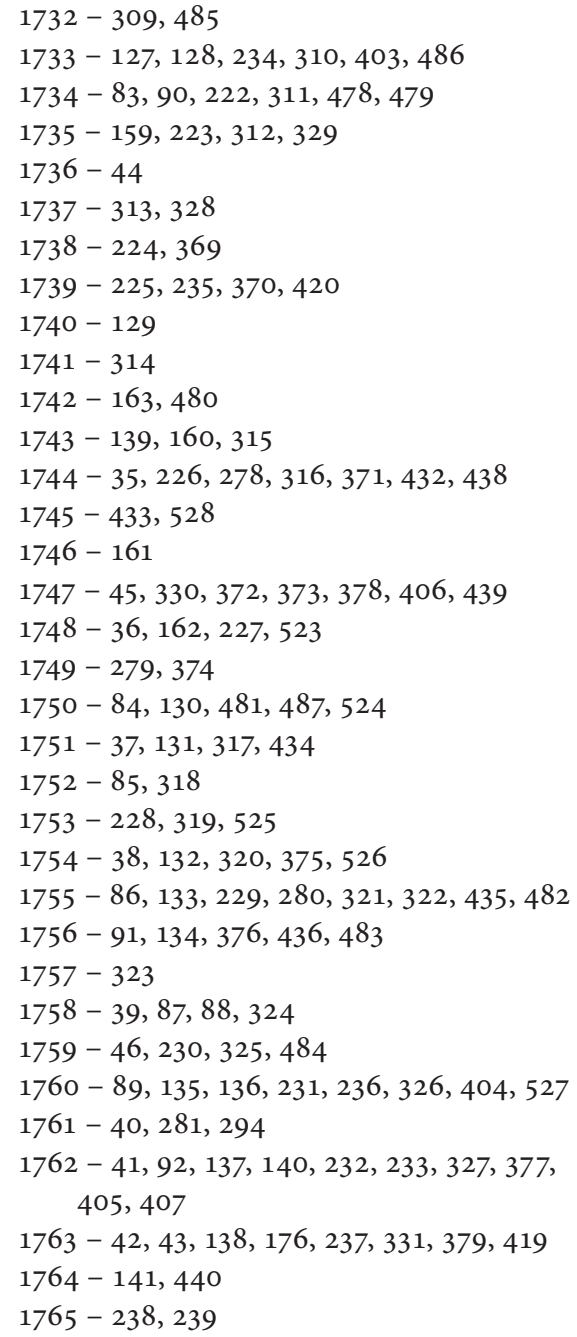

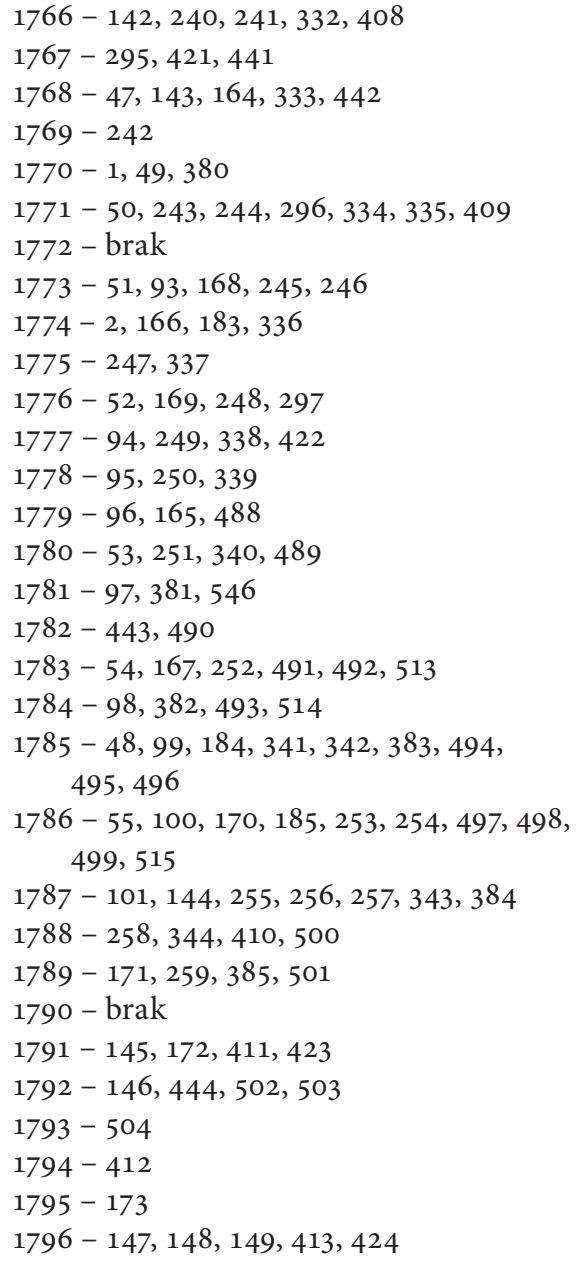

\section{Summary}

\section{The Extant Entries from the Narol Parish Records of the 17th -18 th Century}

The parish in Narol was established by Florian Łaszcz Nieledewski in 1595, in a village existing from the mid-16th century, near which he founded the town of Florianów (now Narol) in 1592. Visitations by bishops of Chełm, in whose 
dioceses Narol was located, confirm that the parish records (births, marriages) were kept from the very beginnings of the parish but in the autumn of 1648 they were destroyed during the Cossack-Tatar invasion (most probably burnt). The new records were kept from 1650. In the early 20 th century they were seen in the Narol church by Karol Notz, famous in Galicia (Eastern Europe) for making inventories of historic relics. In 1914, the parish books were burnt during the fire of the town and the church. Their only known traces, discussed in the present publication, are excerpts/copies made in the mid-19th century by Ludwik Zielinski, which mostly refer to the noble families connected with Narol. The overwhelming majority of the 546 extracts are birth entries, only 29 being records of marriages.

\section{Bibliografia}

\section{Źródła drukowane}

Archidiecezja Lwowska obrzadku łacińskiego w latach 1914-1918. Materiały źródłowe, t. 1, wyd. G. Chajko, Kraków 2018.

\section{Literatura}

Charewiczowa Ł., Historiografia i miłośnictwo Lwowa, Lwów 1938.

Gmiterek H., Fundacja parafii w Narolu i jej losy w przedrozbiorowej Rzeczypospolitej, „Limes. Studia i Materiały z Dziejów Europy Środkowo-Wschodniej”, t. 11, 2018, s. 294-311.

Janas E., Narol na mapie polskich dziejów wojskowych XVII wieku, „Rocznik Lubaczowski", t. 5, 1994, s. 39-41.

Jop R., Metryki ślubów parafii pw. św. Marii Magdaleny w Łęcznej 1622-1768, Lublin 2020. Kupisz D., Księga metrykalna kościoła pod wezwaniem św. Michała Archanioła w Zebrzydowicach $z$ lat 1628-1776, Warszawa 2021.

Literatura w Galicji (1772-1848). Ustęp z pamiętnika Władysława Zawadzkiego, Lwów 1878. Makara S. P., Mazur J., Materiaty do dziejów Narola i Lipska, „Rocznik Lubaczowski”, t. 8, 1998, s. 173-188.

Pizun Z., Gawryś R., Właściciele ziemscy w miasteczku Lubycza Królewska (1787-1939), „Rocznik Tomaszowski”, R. 6, 2017, s. 19-41.

Rachwał P., Ruch naturalny ludności rzymskokatolickiej w Lubelskiem w świetle rejestracji metrykalnej z lat 1582-1900, Lublin 2019. 
Szczygieł R., Lokacja Florianowa na tle urbanizacji Środkowego i Wschodniego Roztocza w XVI i pierwszej połowie XVII wieku, „Rocznik Lubaczowski”, t. 5, 1994, s. 5-16.

Zielińska T., Zbiór Aleksandra Czołowskiego w Archiwum Głównym Akt Dawnych, „Archeion”, t. 89, 1991, s. 37-60.

Zieliński L., Narol - Lubycza - Rawa - Żółkiew, „Lwowianin” 1842, z. 2, s. 45-51. 